\title{
Seasonal variability of the oxygen minimum zone off Peru in a high-resolution regional coupled model
}

\author{
Oscar Vergara ${ }^{1}$, Boris Dewitte ${ }^{1,3,4,5}$, Ivonne Montes $^{2}$, Veronique Garçon ${ }^{1}$, Marcel Ramos ${ }^{3,4,5}$, Aurélien Paulmier ${ }^{1}$, and \\ Oscar Pizarro $^{6,7}$ \\ ${ }^{1}$ Laboratoire d'Études en Géophysique et Océanographie Spatiales, CNRS/IRD/CNES/UPS, UMR5566, Toulouse, France \\ ${ }^{2}$ Instituto Geofísico del Perú (IGP), Lima, Perú \\ ${ }^{3}$ Departamento de Biología, Facultad de Ciencias del Mar, Universidad Católica del Norte, Coquimbo, Chile \\ ${ }^{4}$ Millennium Nucleus for Ecology and Sustainable Management of Oceanic Islands (ESMOI), Coquimbo, Chile \\ ${ }^{5}$ Centro de Estudios Avanzado en Zonas Áridas (CEAZA), Coquimbo, Chile \\ ${ }^{6}$ Department of Geophysics, University of Concepción, Concepción, Chile \\ ${ }^{7}$ Millennium Institute of Oceanography, University of Concepción, Concepción, Chile
}

Correspondence to: Oscar Vergara (oscar.vergara@legos.obs-mip.fr)

Received: 8 December 2015 - Published in Biogeosciences Discuss.: 18 January 2016

Revised: 16 June 2016 - Accepted: 17 June 2016 - Published: 8 August 2016

\begin{abstract}
In addition to being one of the most productive upwelling systems, the oceanic region off Peru is embedded in one of the most extensive oxygen minimum zones (OMZs) of the world ocean. The dynamics of the OMZ off Peru remain uncertain, partly due to the scarcity of data and to the ubiquitous role of mesoscale activity on the circulation and biogeochemistry. Here we use a high-resolution coupled physical/biogeochemical model simulation to investigate the seasonal variability of the OMZ off Peru. The focus is on characterizing the seasonal cycle in dissolved $\mathrm{O}_{2}$ (DO) eddy flux at the OMZ boundaries, including the coastal domain, viewed here as the eastern boundary of the OMZ, considering that the mean DO eddy flux in these zones has a significant contribution to the total DO flux. The results indicate that the seasonal variations of the OMZ can be interpreted as resulting from the seasonal modulation of the mesoscale activity. Along the coast, despite the increased seasonal low DO water upwelling, the DO peaks homogeneously over the water column and within the Peru Undercurrent (PUC) in austral winter, which results from mixing associated with the increase in both the intraseasonal wind variability and baroclinic instability of the PUC. The coastal ocean acts therefore as a source of DO in austral winter for the OMZ core, through eddy-induced offshore transport that is also shown to peak in austral winter. In the open ocean, the OMZ can be divided vertically into two zones: an upper zone above $400 \mathrm{~m}$,
\end{abstract}

where the mean DO eddy flux is larger on average than the mean seasonal DO flux and varies seasonally, and a lower part, where the mean seasonal DO flux exhibits verticalzonal propagating features that share similar characteristics than those of the energy flux associated with the annual extratropical Rossby waves. At the OMZ meridional boundaries where the mean DO eddy flux is large, the DO eddy flux has also a marked seasonal cycle that peaks in austral winter (spring) at the northern (southern) boundary. In the model, the amplitude of the seasonal cycle is $70 \%$ larger at the southern boundary than at the northern boundary. Our results suggest the existence of distinct seasonal regimes for the ventilation of the OMZ by eddies at its boundaries. Implications for understanding the OMZ variability at longer timescales are discussed.

\section{Introduction}

In addition to hosting one of the most productive upwelling systems, the South Eastern Pacific (SEP) is home to one of the most extensive oxygen minimum zones (OMZs) of the world ocean (Fuenzalida et al., 2009; Paulmier and RuizPino, 2009). These oxygen-deficient regions are key to understanding the role of the ocean in the greenhouse gas budget, in climate and in the presently unbalanced nitrogen cy- 
cle (Gruber, 2008). The OMZs represent a net nitrogen loss to the atmosphere in the form of $\mathrm{N}_{2} \mathrm{O}$ (particularly the SEP OMZ; Farías et al., 2007; Arévalo-Martínez et al., 2015) in addition with other toxic or climatically active gases, such as $\mathrm{H}_{2} \mathrm{~S}$ and $\mathrm{CH}_{4}$, respectively, in extremely low dissolved oxygen (DO) concentrations (Libes, 1992; Law et al., 2013). They might even limit the ocean carbon sequestration and act as $\mathrm{CO}_{2}$ sources for the atmosphere (Paulmier et al., 2008, 2011). Furthermore, the OMZs contribute to the habitat compression of marine organisms, in a zone that sustains $10 \%$ of the world fish catch (Prince and Goodyear, 2006; Chavez et al., 2008). Therefore, understanding the dynamics behind the OMZ becomes not just a matter of scientific interest but also a major societal concern.

In general, these low-oxygen regions are considered to result from the interaction of biogeochemical and physical processes (Karstensen et al., 2008). The SEP presents high biological productivity, inducing a significant DO consumption mainly through the remineralization associated with a complex nutrient cycle supported by the intense upwelling. In addition, the SEP encompasses a so-called "shadow zone", a near stagnant/sluggish circulation region next to the eastern basin boundary, not ventilated by the basin-scale wind-driven circulation (Luyten et al., 1983). Assuming a steady state, lateral oxygen fluxes from subtropical water masses and diapycnal mixing are expected to balance the oxygen consumption (Brandt et al., 2015). However, the diversity of environmental forcings in the SEP and the variety of timescales at which they operate (Pizarro et al., 2002; Dewitte et al., 2011, 2012) have eluded a proper understanding of the processes controlling the OMZ structure and variability. On the one hand, the scarcity of data and rare surveys have only permitted the documentation of the DO temporal variability at a few locations (e.g., Morales et al., 1999; Cornejo et al., 2006; Gutiérrez et al., 2008; Llanillo et al., 2013). On the other hand, the highly complex interaction between physical and biogeochemical mechanisms makes modeling and prediction of OMZ location, intensity and its temporal variability a challenging task (Karstensen et al., 2008; Cabré et al., 2015). Low-resolution CMIP class coupled models still have severe biases of physical and biogeochemical origins, particularly in eastern boundary current systems (Richter, 2015), which has eluded the interpretation of long-term trends in OMZ (Stramma et al., 2008, 2012; Cabré et al., 2015). Regional coupled biogeochemical modeling nonetheless has provided a complementary approach to gain insight in the dynamics of OMZ and its relationship with climate (Resplandy et al., 2012; Gutknecht et al., 2013a). One recent modeling effort to understand the dynamics behind the OMZ in the eastern tropical Pacific comes from Montes et al. (2014). This study provided a first regional simulation of the OMZ in the SEP and summarized the elements involved in maintaining the OMZ found off the coast of Peru as the result of a delicate balance of (i) the equatorial current system dynamics - the relatively oxygen-rich waters carried by the Equatorial Un- dercurrent (EUC), the relatively oxygen-poor and nutrientrich waters carried by the primary and secondary Tsuchiya Jets (primary and secondary southern subsurface countercurrents) - and (ii) the high surface productivity rates induced by the coastal upwelling, which in turn triggers an intense oxygen consumption in the subsurface. Their model experiments also showed that different eddy kinetic energy (EKE) levels, induced by different representations of the mean vertical structure of the coastal current, may contribute to the expansion or erosion of the upper boundary of the OMZ.

The study by Montes et al. (2014) established a benchmark in terms of numerical modeling of the OMZ in the SEP, focusing on its permanent regime and connection with the equatorial current dynamics. In the present study, we also take advantage of the regional modeling approach in order to investigate the mechanisms associated with the seasonal cycle of DO within the OMZ. The motivation for focusing on seasonal variability is threefold: (1) a better knowledge of the processes acting on the OMZ at seasonal timescale is viewed as a prerequisite for interpreting longer timescales of variability (ENSO, decadal); (2) the scarcity of quality longterm subsurface biogeochemical data in the SEP is a limitation for tackling the investigation of OMZ variability at low frequency; (3) to the authors' knowledge, this issue has not been addressed in the literature for the eastern tropical $\mathrm{Pa}$ cific, although it has been a concern for other tropical oceans (Resplandy et al., 2012; Gutknecht et al., 2013a; Duteil et al., 2014).

Here, besides investigating to what extent the seasonal $\mathrm{OMZ}$ variability can relate to the variability of the environmental forcing in the SEP (local wind, equatorial Kelvin and extratropical Rossby waves, hereby referred to as ETRW), our interest is on examining the DO budget (i.e., the balance between oxygen sources and sinks) and relating it to the physical DO flux. In particular, since the Peruvian region is the location of relatively intense eddy activity (Chaigneau et al., 2009), the question of whether or not eddy activity is involved in the seasonal variability of the OMZ arises and calls for assessing its contribution to the DO flux. There is growing evidence that the mesoscale activity plays a key role in the biogeochemical cycles and the OMZ structure in eastern boundary upwelling systems (Duteil and Oschlies, 2011; Nagai et al., 2015). Most studies addressing the role of mesoscale processes in the OMZs have focused on the ventilation from the coastal domain, where the primary production bloom provides nutrients and DO anomalies that are in turn transported offshore (Stramma et al., 2013; Czeschel et al., 2015; Thomsen et al., 2016). Gruber et al. (2011) showed that mesoscale activity is prone to reducing the biological production and offshore carbon export in upwelling systems by both rectifying on the mean circulation (i.e., eddy-induced mixing tends to flatten the isotherms nearshore and reduce the upwelling) and changing its nutrient transport capacity. This process has been to some extent supported by observations in the Peruvian OMZ (Stramma et al., 2013). In this sense, 
the mesoscale activity represents a ventilation pathway for the OMZ, through the offshore transport of oxygen-enriched waters. The ventilation of the OMZ could also take place at its meridional boundaries where strong mean DO gradients are found along with eddy activity. Recently, Bettencourt et al. (2015) proposed that mesoscale eddies shape the Peruvian $\mathrm{OMZ}$ by controlling the diffusion of DO into the OMZ at the meridional boundaries. Although it is likely that both processes are important for understanding the OMZ structure, it has not been clarified to which extent the variability of the OMZ could be understood in terms of the changes in the DO eddy flux into the OMZ through these different pathways. The mesoscale activity also exhibits a significant meridional variability off Peru (Chaigneau et al., 2009), which questions whether the offshore ventilation process can operate effectively for modulating the whole OMZ. Another related open question is at which timescales the ventilation process through eddies-induced mixing can operate effectively. In this paper we will tackle these issues from a regional modeling approach, focusing on the seasonal timescale.

The paper is organized as follows. After the introduction (Sect. 1), we detail the observations and model configuration used in the study, as well as the methodology employed in the treatment of the information (Sect. 2). We also evaluate the realism of the simulation against the available observations in reproducing the main characteristics of the OMZ. The subsequent section (Sect. 3) characterizes the DO annual cycle inside the OMZ. Section 4 opens with the analysis of the seasonal variability of the coastal OMZ and the contribution of the DO budget terms associated with it. This analysis is followed by the results of DO flux directed offshore and completed by the analysis of DO flux across the OMZ meridional boundaries. Section 5 presents a discussion of the main results and Sect. 6 presents a summary and the concluding remarks.

\section{Data description and methods}

\subsection{Data}

\subsubsection{Dissolved oxygen concentration from the CSIRO Atlas of Regional Seas (CARS)}

CARS is a climatological product derived from a qualitycontrolled archive of historical subsurface ocean measurements, most of which were collected during the past 50 years (additional information might be found on the website of the project: http://www.marine.csiro.au/ dunn/cars2009/). For the present study, we use the CARS2009 version of the CARS product (Ridgway et al., 2002), which has an horizontal resolution of $0.5^{\circ} \times 0.5^{\circ}$ and 79 vertical levels, with a $10 \mathrm{~m}$ resolution near the surface layer. We use CARS to assess the model's skills in simulating the OMZ mean state and variability. One advantage of this product is its refined interpolation treatment near steep topography in comparison to other products such as the World Ocean Atlas (Dunn and Ridgway, 2002). Also, it includes the annual and semiannual oxygen cycles, although the semiannual cycle is available only for the first $375 \mathrm{~m}$ over the region of interest due to the scarcity of data.

\subsubsection{Chlorophyll $a$ concentration from SeaWiFS}

Eight-day composites at $0.5^{\circ} \times 0.5^{\circ}$ resolution of the SeaWiFS chlorophyll product (version 4), between January 2000 and December 2008, are used to compute the surface chlorophyll seasonal cycle (McClain et al., 1998; O'Reilly et al., 2000).

\subsubsection{Sea surface temperature (SST)}

The NOAA Optimum Interpolation SST (OISST V2) product is contrasted against the simulation SST. This product is an analysis constructed by combining observations from different platforms (satellites, ships, buoys) on a regular global grid. More information about the methodology used to construct this data set may be found in Reynolds et al. (2007) and the product website (https://www.ncdc.noaa.gov/oisst). The version used in this study corresponds to daily SST maps with a spatial resolution of $0.25^{\circ} \times 0.25^{\circ}$, spanning the period 2000-2008.

\subsubsection{Sea level height (SLH)}

The TOPEX/JASON1-2 merged SLH data set, distributed by the Sea Level Research Group, University of Colorado (http: //sealevel.colorado.edu/), is used to derive the geostrophic velocity field and the mean EKE field. This data set corresponds to a globally gridded $0.25^{\circ} \times 0.25^{\circ}$ weekly product. The information used corresponds to the period 1993-2008. Further details on this product may be found in Nerem et al. (2010).

\subsection{Model simulation}

We use a high-resolution simulation of the southeastern $\mathrm{Pa}$ cific, based on the hydrodynamic Regional Ocean Modeling System (ROMS) circulation model (see Shchepetkin and McWilliams, 2005, 2009, for a complete description of the model) coupled with a nitrogen-based biogeochemical model developed for the eastern boundary upwelling systems (BioEBUS; Gutknecht et al., 2013a, b), hereby referred as CR BIO.

The model is used at an eddy-resolving resolution $\left(1 / 12^{\circ}\right.$ at the Equator) for a region extending from $12^{\circ} \mathrm{N}$ to $40^{\circ} \mathrm{S}$ and from the coast to $95^{\circ} \mathrm{W}$ - although this study only focuses on the domain spanning the latitudes of Peru and Ecuador (Fig. 1) - with lateral open boundaries at its northern, southern and western frontiers. The physical model resolves the hydrostatic primitive equations with a free-surface 

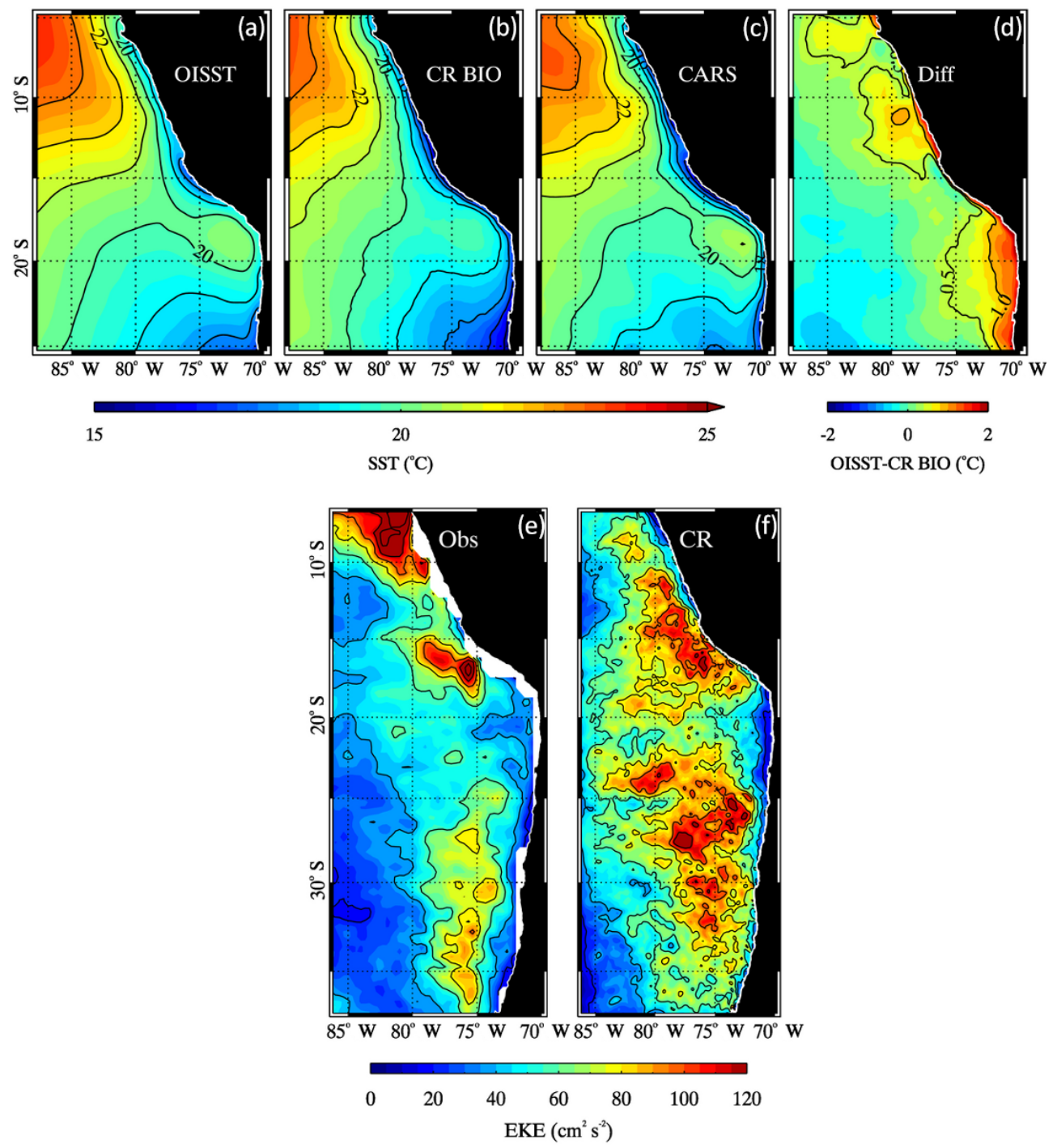

Figure 1. Mean sea surface temperature (SST) between 2000 and 2008 for (a) OISST product $\left(0.25^{\circ} \times 0.25^{\circ}\right),\left(\right.$ b) the simulation $\left(1 / 12^{\circ}\right)$ and (c) CARS data set $\left(0.5^{\circ} \times 0.5^{\circ}\right)$. (d) Difference between the OISST product and the simulation. Mean eddy kinetic energy (EKE) between 1993 and 2008, for (e) TOPEX/Poseidon Jason 1-2 merged product $\left(0.25^{\circ} \times 0.25^{\circ}\right)$, and (f) simulation $\left(1 / 12^{\circ}\right)$. EKE was derived from the interannual anomalies of the geostrophic velocity field.

explicit scheme and a stretched terrain-following sigma coordinates on 37 vertical levels. The configuration is similar to Dewitte et al. (2012), that is the open boundary conditions are provided by 5-day mean oceanic outputs from SODA (Version 2.1.6) for temperature, salinity, horizontal velocity and sea level for the period 1958-2008, while wind stress and speed forcing at the air/sea interface come from the NCEP/NCAR reanalysis. The atmospheric fields have been statistically downscaled following the method by Goubanova et al. (2011) in order to correct for the unrealistic wind stress curl near the coast of the NCEP Reanalysis (see Cambon et al., 2013, for a validation of the method for oceanic applications). Atmospheric fluxes were derived from the bulk formula using the temperature from COADS $1^{\circ} \times 1^{\circ}$ monthly climatology (daSilva et al., 1994). Relative humidity and shortwave and long-wave radiations are also from COADS. Bottom topography is from the GEBCO 30 arcsec grid data set, interpolated to the model grid and smoothed as in Penven et al. (2005) in order to minimize the pressure gradient errors and modified at the boundaries to match the SODA bottom topography. This model configuration has been validated from satellite and in situ observations in Dewitte et al. (2012) with a focus on mean state interannual variability. In general the model is skillful in simulating the mean SST field (Fig. 1a, c) as well as other main aspects of the mean circulation (e.g., Peru/Chile Undercurrent, EKE; see Fig. 3 in Dewitte et al., 2012), although with a slight cold 

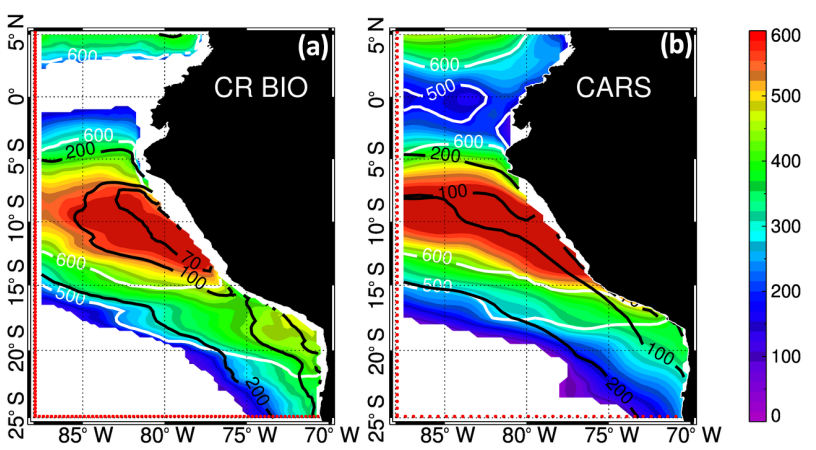

Figure 2. Mean oxygen minimum zone core thickness (color scale in meters) for (a) the simulation and (b) CARS. Depths of the lower (white) and upper (black) limits of the OMZ core are also depicted. The OMZ core is defined as $[\mathrm{DO}]<20 \mu \mathrm{M}$. The red dots denote the horizontal resolution of the DO field.

bias $\left(\sim 1^{\circ} \mathrm{C}\right)$ that could be partly attributed to the use of climatological heat flux forcing (Fig. 1d).

The mesoscale activity diagnosed from the mean EKE, has a comparable pattern than altimetry, although with a larger amplitude (Fig. 1e, f). Similar levels of mesoscale activity have been obtained by previous modeling studies in the Peruvian region (e.g., Echevin et al., 2011; Colas et al., 2012).

The ocean model within this configuration is coupled to the BioEBUS model following similar methodology than Montes et al. (2014). BioEBUS uses two compartments of phytoplankton and zooplankton, small (flagellates and ciliates, respectively) and large (diatoms and copepods, respectively), detritus, dissolved organic nitrogen and the inorganic nitrogen forms nitrate, nitrite and ammonium, as well as nitrous oxide (see Gutknecht et al., 2013a, b, for a description of the model). The open-boundary conditions for the biogeochemical model are provided by the climatological CARS data set (nitrate and oxygen concentrations) and by SeaWiFS archive (chlorophyll $a$ concentration). Additional biogeochemical tracers are computed following Gutknecht et al. (2013a, b). Initial phytoplankton concentration is defined as a function of vertically extrapolated satellite Chl $a$ following Morel and Berthon (1989). An offshore decreasing cross-shore profile, following in situ observations, is applied for zooplankton, and a vertical constant (exponential) profile is used for detritus (nitrite, ammonium and dissolved organic nitrogen). In order to get a realistic solution for the region, the model parameters were tuned to simultaneously fit modeled oxygen and nitrate fields to observations (see Table A1 of Montes et al. (2014) for parameter values). These changes were motivated by the need to adjust the microbiological rates to values observed in the SEP. Within this parameter configuration, BioEBUS has been shown to be skillful for simulating the OMZ off Peru (Montes et al., 2014). In particular the pattern correlations between the model and observations for both the annual mean and the seasonal cycle inside the OMZ present comparable scores $(>0.85$, cf.
Montes et al., 2014) as well as low standard deviations (i.e., in the order of the observed values). The model was run over the period 1958-2008 with a 10-year spin-up obtained by repeating the year 1958. Although, after the spin-up, the simulation has reached stable conditions and the OMZ volume does not drift, we focus in the present study only on the period 2000-2008.

The reason for focusing on the last 10 years of our simulation is also motivated by the fact that the atmospheric momentum forcing is close to the satellite QuickSCAT winds by construction (see Goubanova et al., 2011, for details) so that this period of the simulation is the one when the model is the most constrained by observations. Most previous modeling studies for this region (Penven, et al. 2005; Montes et al., 2010, 2014; Echevin et al., 2011; Colas et al., 2012) have also used a wind forcing from the QuickSCAT scatterometer, which provides a benchmark for assessing our simulation.

A monthly-mean climatology is calculated for all variables over this period from the 3-day mean outputs of the model, which can be compared to the CARS data.

Consistently with Montes et al. (2014), the coupled simulation is skillful in simulating the mean characteristics of the OMZ off the Peruvian coast (Figs. 2 and 3). In particular the thickness and location of the model OMZ core limits are realistic, and in good agreement with previous studies (Fig. 2; e.g., Paulmier et al., 2006; Cornejo and Farías, 2012; Montes et al., 2014). Note that the simulation reproduces a thinner $\mathrm{OMZ}$ around $10^{\circ} \mathrm{S}$ in comparison to CARS, which agrees with the results obtained by Montes et al. (2014) (see Fig. 2 in that study). Close to the western boundary of our model domain, the simulated $\mathrm{OMZ}$ also exhibits a realistic vertical structure (Fig. 3) with comparable concentration in DO than observations in the vicinity of the Equatorial Undercurrent ( $\sim 100 \mathrm{~m}$; Equator). Furthermore, the simulation is consistent in reproducing the oxygen-consuming processes, as supported by the apparent oxygen utilization (AOU; Fig. 4), also in good agreement with previous studies (cf. Fig. 8 in Cabré et al., 2015). AOU was computed as the difference between the DO concentration and the saturated oxygen $\left(\mathrm{O}_{2}\right.$ sat $)$ concentration $\left(\mathrm{AOU}=\mathrm{O}_{2}\right.$ sat- $\mathrm{O}_{2}$ ) with $\mathrm{O}_{2}$ sat computed following the methodology of García and Gordon (1992). The realistic representation of the oxygen-consuming processes is reflected by the particulate organic carbon flux as well (Fig. 5a), whose values at $100 \mathrm{~m}$ fall within the observed range for the region $\left(30-60 \mathrm{gC} \mathrm{m}^{-2} \mathrm{yr}^{-1}\right.$ in the shelf area; Dunne et al., 2005; Henson et al., 2012). In addition, the low transfer efficiency of carbon (10-15\% or lower over and next to the shelf; Henson et al., 2012), from the euphotic zone to greater depths (Fig. 5b), implies that the remineralization processes take place at realistic depths and therefore allow for a correct vertical representation of the OMZ (cf. Fig. S2 in Cabré et al., 2015, for comparison).

The core of the OMZ, defined with a suboxic concentration ([DO] $<20 \mu \mathrm{M} ; \mu \mathrm{M}$ will be used to refer to $\mu \mathrm{mol} \mathrm{L}-1$ in all the text and figures), occupies nearly $23 \%$ of the 

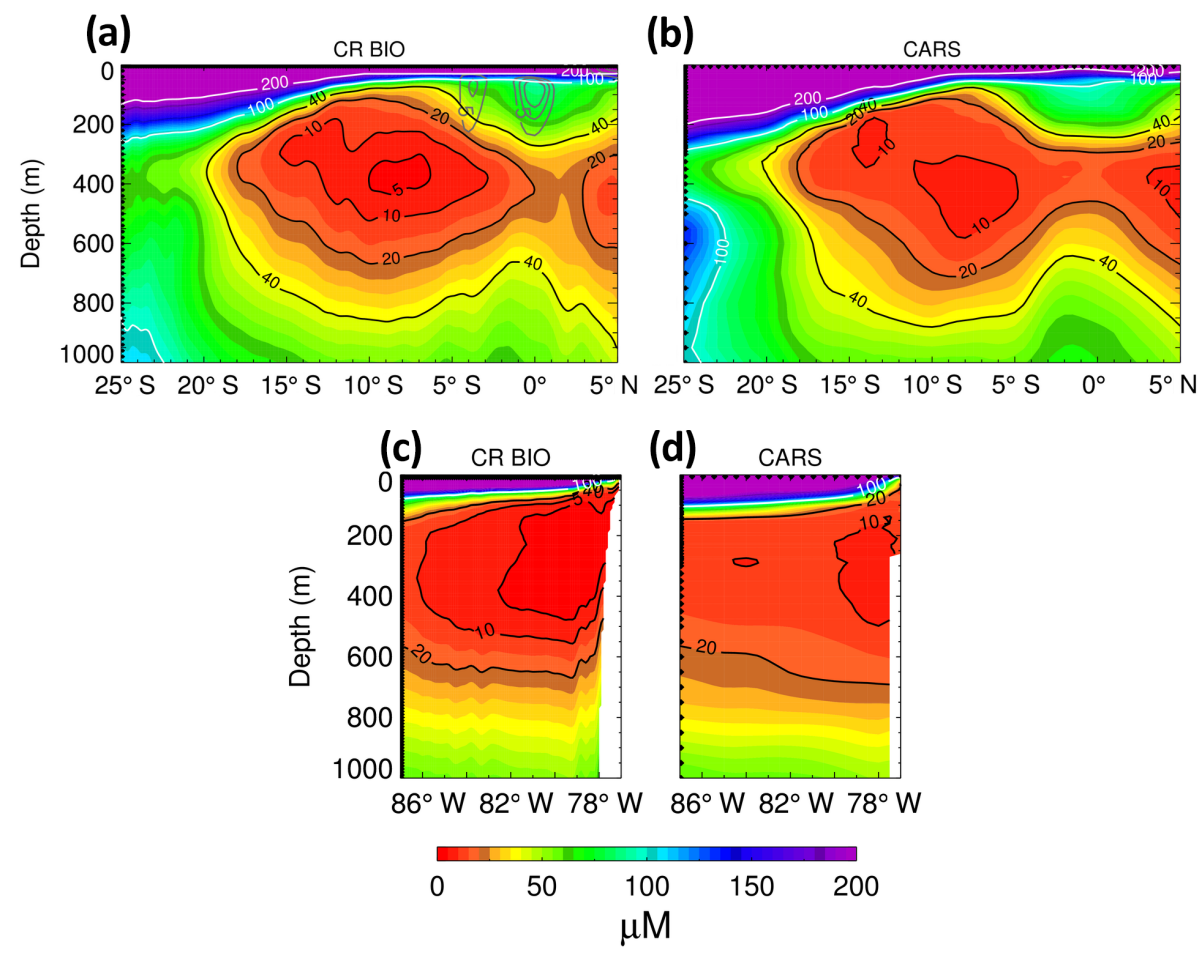

Figure 3. Mean oxygen concentration for a meridional section at $85^{\circ} \mathrm{W}(\mathbf{a}, \mathbf{b})$ and a cross-shore section at $12^{\circ} \mathrm{S}(\mathbf{c}, \mathbf{d})$, for both the simulation and CARS. Gray contours in (a) show mean zonal speed of 5, 10 and $15 \mathrm{~cm} \mathrm{~s}^{-1}$, respectively. The black dots denote the horizontal and vertical resolution of the DO field.

domain volume (Fig. 6a), with the less oxygenated layers comprised between 5 and $15^{\circ} \mathrm{S}$, and 100 and $600 \mathrm{~m}$ depth (Fig. 3). As expected, the simulation presents more details than the climatological product (Fig. 3). Moreover, we computed a geographical OMZ overlapping metric following Cabré et al. (2015), which quantifies the spatial agreement of the OMZ volume distribution between the simulation and CARS, varying between 0 (no agreement) and 1 (perfect collocation). We obtained a value of 0.79 , which is $\sim 58 \%$ above the best CMIP5 models used in Cabré et al. (2015).

Despite the overall good agreement between the model and observations, the simulation overestimates the oxygen content in certain regions of the domain as compared to CARS, particularly southwards of $20^{\circ} \mathrm{S}$ (Fig. 3a) and close to the coast (Fig. 3d). The simulation also underestimates by $6 \%$ the volume of suboxic water (Fig. 6a), which is comparable to the differences obtained by Montes et al. (2014) using the same model within a different configuration and boundary forcing.

The modeled DO distribution is also characterized by finer spatial scales of variability inside the OMZ compared to observations (Fig. 3c and d). In particular, the model oxycline is shallower and with a more intense DO gradient than the observations, which has been also observed in a regional simulation of the Arabian Sea OMZ (Resplandy et al., 2012). While this could be partly due to CARS underestimating the
DO gradient, as a result of its relatively low vertical resolution, it could also be that the model underestimates the vertical diffusivity in the vicinity of the oxycline. Also, it must be kept in mind that CARS is built using all the available data from the second half of the twentieth century (1940-2009), whereas we focus on the period 2000-2008 for the simulation, which is known to be a colder period than the previous decades in the eastern tropical Pacific (Henley et al., 2015). Other limitations for the comparison between model and data include the errors associated with the scarcity of data in some regions (Bianchi et al., 2012) and biases in model parametrizations. Nonetheless, the simulation is in overall good agreement with CARS in terms of mean characteristics of the OMZ (Figs. 4, 6a).

In order to evaluate the realism of the seasonal cycle, we estimate the seasonal variability of the volume of water within the suboxic DO concentration range $0-20 \mu \mathrm{M}$ in both the model and data (Fig. 6b). The results indicate that, despite a weaker amplitude (by $15 \%$ on average), the seasonal cycle of the OMZ core is relatively well simulated by the model. For hypoxic DO volume in the range $40-50 \mu \mathrm{M}$, the agreement is as good as inside the OMZ core, with a Pearson correlation value of 0.9 and a volume root mean square (RMS) difference of $16 \%$, between the simulation and the observations. 

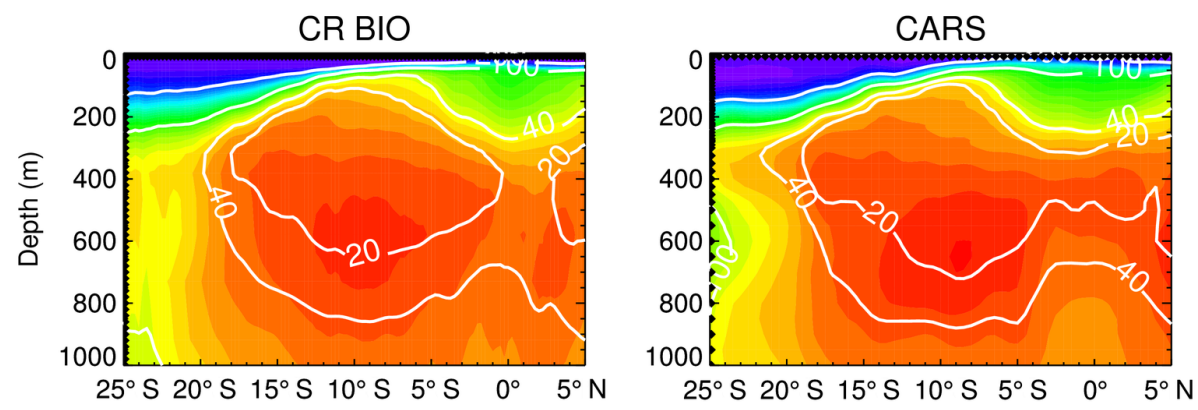

\begin{tabular}{lllllll}
\hline 0 & 50 & 100 & $\begin{array}{c}150 \\
\mu M\end{array}$ & 200 & 250 & 300 \\
& & & &
\end{tabular}

Figure 4. Mean apparent oxygen utilization (AOU) at $85^{\circ} \mathrm{W}$ for both $\mathrm{CR} \mathrm{BIO}$ and CARS. White contours denote the mean oxygen concentration isopleths (in $\mu \mathrm{M}$ ). The black dots denote the horizontal and vertical resolution of the DO field.

In order to summarize the model validation, we present a Taylor diagram showing the statistics of the comparison between the model and observations for a depth range encompassing the OMZ (Fig. 7). This analysis indicates that within the present model configuration, we reach a skill comparable to the model configuration of Montes et al. (2014) (their Fig. 1). The good agreement of the seasonal cycle between CARS and the simulation, in addition to the consistency of our results with those of Montes et al. (2014), provides confidence in using the model outputs for investigating the processes associated with the seasonal variability of the OMZ.

\subsection{Methods}

In this work, our approach is twofold: First, the biogeochemical processes for DO are investigated explicitly through the online oxygen budget. Although this methodology can provide a direct estimate of the seasonal variability in advection and mixing, it does not allow for a direct estimate of the eddy contribution to DO change that can also vary seasonally. The DO flux associated with different timescales of variability is therefore estimated. This consists in computing the temporal average of the cross-products between DO and velocity anomalies. Anomalies can refer either to seasonal anomalies (in that case, this provides the mean seasonal DO flux: $\left\langle\widetilde{u} \times \widetilde{\mathrm{O}}_{2}\right\rangle$, where $\sim$ refers to the seasonal anomalies) or to the intraseasonal anomalies, calculated here as the departure from the monthly mean (in that case, this provides an estimate of the mean DO eddy flux: $\left\langle u^{\prime} \times \mathrm{O}_{2}^{\prime}\right\rangle$, where the apostrophe refers to the intraseasonal anomalies). In this paper we are also interested in the seasonality of the DO eddy flux. This is estimated from the monthly-mean seasonal cycle of the mean DO eddy flux calculated over a 3-month running window and is now referred to as $\overline{\left\langle u^{\prime} \times \mathrm{O}_{2}^{\prime}\right\rangle}$. The climatological EKE activity is estimated similarly.

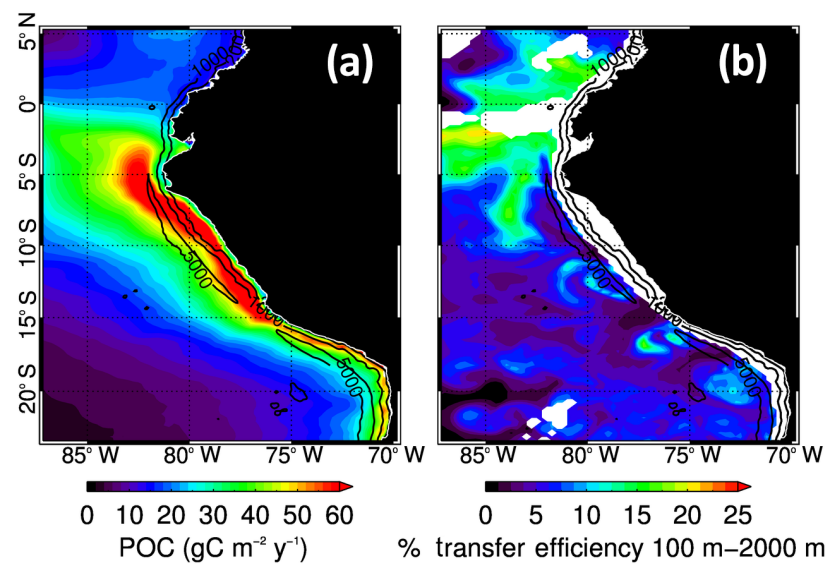

Figure 5. (a) Particulate organic carbon (POC) flux at $100 \mathrm{~m}$ and (b) POC transfer efficiency between 100 and $2000 \mathrm{~m}$ (POC flux at $2000 \mathrm{~m}$ divided by POC flux at $100 \mathrm{~m}$ ), computed from the simulation. Integrated carbon flux at the depth of $100 \mathrm{~m}$ is $0.8 \mathrm{Pg} \mathrm{C} \mathrm{yr}^{-1}$. Black contours correspond to the 200,1000 and $5000 \mathrm{~m}$ isobaths.

The DO budget consists in the following equation:

$\frac{\partial \mathrm{O}_{2}}{\partial t}=-\boldsymbol{u} \cdot\left(\nabla \mathrm{O}_{2}\right)+K_{h} \cdot \nabla^{2} \mathrm{O}_{2}+\frac{\partial}{\partial z}\left(K_{Z} \frac{\partial \mathrm{O}_{2}}{\partial z}\right)+\operatorname{SMS}\left(\mathrm{O}_{2}\right)$.

The first three terms on the right-hand side represent the physical processes involved in the changes in oxygen concentration. The first term stands for the advection of oxygen, where $\boldsymbol{u}$ is the velocity vector (note that the model determines the vertical velocity component from the continuity equation). The second term corresponds to the horizontal subgridscale diffusivity (with $K_{h}$ the eddy diffusion coefficient equal to $100 \mathrm{~m}^{2} \mathrm{~s}^{-1}$ in this version of the model), and the third term corresponds to the vertical mixing (with turbulent diffusion coefficient $K_{z}$ calculated based on the K-profile parameterization mixing scheme; Large et al., 1994). Note that the 
(a)

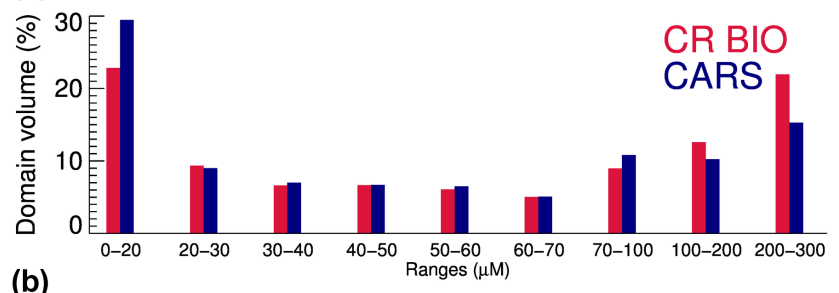

(b)

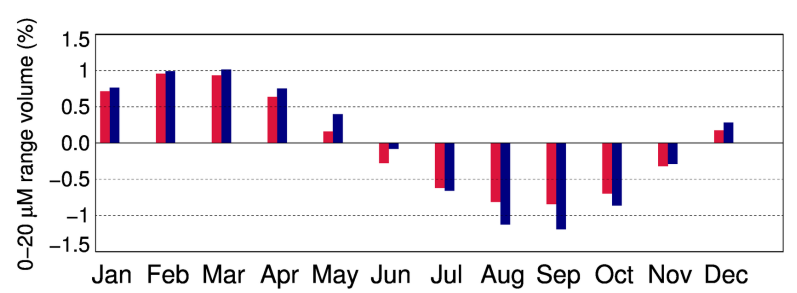

Figure 6. (a) Domain volume distribution $\left(25^{\circ} \mathrm{S}-5^{\circ} \mathrm{N}, 88-70^{\circ} \mathrm{W}\right)$ as a function of the oxygen concentration and (b) annual cycle, relative to the mean, of the volume distribution inside the $\mathrm{OMZ}$ core (DO value range corresponding to $0-20 \mu \mathrm{mol} \mathrm{L}^{-1}$ ), for both CARS and the simulation.

model also has numerical diffusion associated with inherent spurious diapycnal mixing of the numerical scheme, so that $K_{h}$ is empirically adjusted.

The fourth term represents the "source-minus-sink" contribution to the oxygen changes, directly due to biogeochemical activity. Biogeochemical processes correspond to the sum of oxygen sources and sinks, namely the photosynthetic production, and the aerobic processes (oxic decomposition, excretion and nitrification). In this study, for simplicity, those will be considered as a summed-up contribution to the DO rate of change, whereas physical processes will be divided into advection and mixing terms. Each term of this oxygen budget is determined online at each time integration. While horizontal diffusion and vertical diffusivity are explicit sources of mixing, they are not the only terms contributing to mixing. Later on in the paper, unless stated otherwise, the term mixing will refer to the integrated effect of all processes contributing to mixing directly or indirectly. Besides the horizontal diffusion $\left(K_{h} \times \nabla^{2} \mathrm{O}_{2}\right)$ and vertical mixing $\left(\frac{\partial}{\partial z}\left(K_{Z} \frac{\partial \mathrm{O}_{2}}{\partial z}\right)\right)$, mixing can be also induced by nonlinear advection. The latter corresponds to $\left(u^{\prime} \partial u^{\prime} / \partial x\right)+\left(v^{\prime} \partial v^{\prime} / \partial y\right)+$ $\left(w^{\prime} \partial w^{\prime} / \partial z\right)$, assuming the Reynolds decomposition for the velocity field, i.e., $\overline{\boldsymbol{u}}+\boldsymbol{u}^{\prime}$, where $\boldsymbol{u}^{\prime}$ accounts for the intraseasonal variability (periods shorter than $\sim 3$ months).

In the SEP, the subthermocline seasonal variability can be interpreted as resulting from the propagation of ETRW. ETRW radiate from the coast and propagate vertically, inducing a vertical energy flux whose trajectory follows the theoretical Wentzel-Kramers-Brillouin (WKB) ray paths (Dewitte et al., 2008; Ramos et al., 2008). The energy flux results from the phase relationship between vertical velocity associated with the vertical displacement of the isotherms,

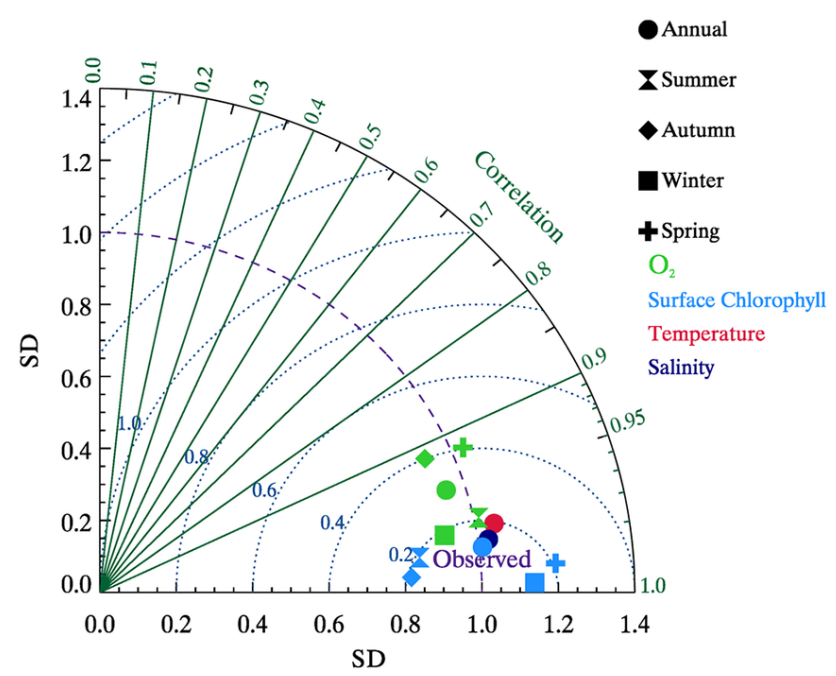

Figure 7. Taylor diagram of the seasonal mean (hourglass, diamond, square and cross) and annual mean (circle) pattern of DO and surface chlorophyll $\left(25^{\circ} \mathrm{S}-5^{\circ} \mathrm{N}, 88-70^{\circ} \mathrm{W}\right)$. Only annual mean pattern comparisons are shown for temperature and salinity (same spatial domain). DO, temperature and salinity were vertically averaged between 100 and $600 \mathrm{~m}$ depth (focus on the OMZ core). Only the surface chlorophyll values within $250 \mathrm{~km}$ next to the coast were considered. The comparisons are made between the simulation and CARS (for DO, temperature and salinity) and SeaWiFS (for surface chlorophyll). Ordinate and abscissa axes represent the standard deviation normalized by the observations standard deviation. Blue dotted radial lines indicate the RMS difference between the observations and the simulation.

and the pressure fluctuations associated with them. In the regions sufficiently below the thermocline for DO consumption to become weak (that is DO can be considered a passive tracer), it is expected that changes in DO relate to the anomalous velocity field and that the DO flux shares comparable characteristics than the Eliassen-Palm flux (Eliassen and Palm, 1960). The trajectories of the WKB ray paths are a function of latitude, local stratification and the phase speed of the Rossby wave (see Ramos et al., 2008). The latter consists in the superposition of a certain number of baroclinic modes, in order to propagate vertically, so the phase speed can range from $c_{1}$ to $c_{n}$, where $c_{n}$ is the theoretical phase speed of a $n$th baroclinic mode, obtained from the vertical mode decomposition of the local density profile.

\section{Characteristics of the DO annual cycle}

While the annual signal is a conspicuous feature inside the region (Fig. 6b), it could manifest differently across the OMZ. As a first step towards investigating processes driving the rate of DO change, it appears important to document the vertical structure variability of the DO annual cycle within the OMZ. The amplitude and phase of the annual harmonic of the model DO climatology are presented along a zonal section 
(a)

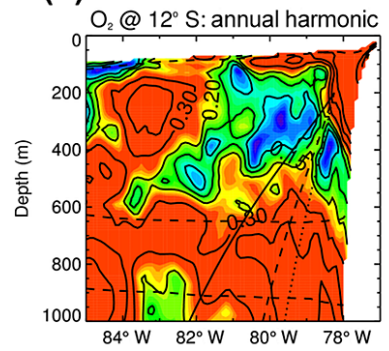

(b)

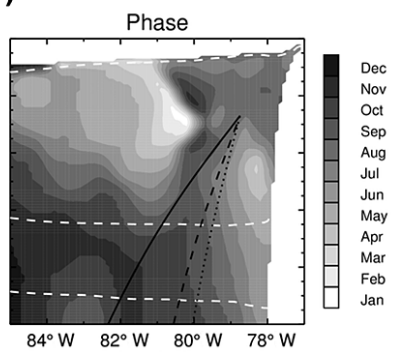

(c)

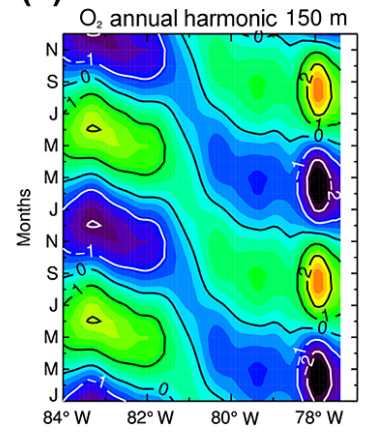

(d)

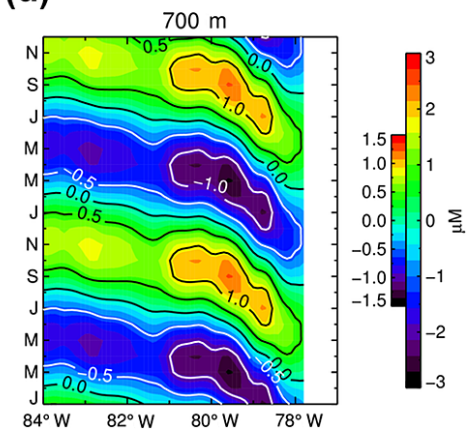

Figure 8. (a) Amplitude and (b) phase of the annual maximum (in months) of the annual harmonic of the normalized DO concentration at $12^{\circ} \mathrm{S}$. The slanted vertical lines indicate the theoretical WKB ray paths at a frequency of $\omega=2 \pi \times 1 \mathrm{yr}^{-1}$, for different values of phase speed. The theoretical trajectories were computed using the phase speed of the first (full), second (dashed) and third (dotted) baroclinic modes of a long Rossby wave. Dashed contours in (a) and (b) depict the 45 and $20 \mu \mathrm{M}$ mean DO values. Land and the region outside the $45 \mu \mathrm{M}$ mean DO isopleth are masked in white. (c) Annual harmonic of the DO concentration at $12^{\circ} \mathrm{S}$, at $150 \mathrm{~m}$ and (d) $700 \mathrm{~m}$ depth. Small color scale corresponds to $700 \mathrm{~m}$ and the large color scale denotes the levels used in (c).

off central Peru $\left(12^{\circ} \mathrm{S}\right.$, Fig. 8a, b), where the OMZ core is extensive (Fig. 2). The DO climatology has been normalized by its RMS in order to emphasize the regions where the amplitude in DO changes (and mean DO) is weak. The amplitude reveals a complex pattern with three regions of large relative variability: (1) near the coast (i.e., fringe of $\sim 150 \mathrm{~km}$ ) between the oxycline and $400 \mathrm{~m}$, (2) offshore between 82 and $84^{\circ} \mathrm{W}$ in the upper $400 \mathrm{~m}$ and (3) below $500 \mathrm{~m}$. The phase lines over these three regions suggest distinct propagating characteristics: whereas in the coastal region there is no propagation, in the offshore and deep region there is indication of a westward propagation. In the region below $500 \mathrm{~m}$, the phase lines tend also to be parallel and slope downward, suggestive of westward-downward propagation (estimated phase speed of $\sim 2.5 \mathrm{~cm} \mathrm{~s}^{-1}$ ). These propagating characteristics can be evidenced in the Hovmöller diagrams of the recomposed annual cycle at the depth of $150 \mathrm{~m}$ (Fig. 8c) and $700 \mathrm{~m}$ (Fig. 8d). While at $150 \mathrm{~m}$ the annual signal does not clearly propagate and only shows two domains of high amplitude, separated by low amplitude values (Fig. 8c) there is a clear westward propagation of the DO anomalies at $700 \mathrm{~m}$, with the phase speed increasing westward. At $400 \mathrm{~m}$, the propagation is only observed west of $81^{\circ} \mathrm{W}$ (Fig. 8b). In addition to the large vertical structure variability of the annual cycle, the OMZ annual cycle is also characterized by a large horizontal variability in particular at its northern and southern boundaries. This is illustrated in Fig. 9, which displays the amplitude of the annual cycle of the DO climatology at $400 \mathrm{~m}$ and evidences amplitude peaks at the OMZ meridional boundaries (between the 20 and $45 \mu \mathrm{M}$ isopleths).

The annual variability pattern evidenced above results from a delicate balance between the physical processes (namely advection and mixing, cf. Eq. 1) and the biogeochemical processes (consumption versus production). As a first step towards investigating each term of the DO budget, it is interesting to evaluate the relative contribution of the physical and biogeochemical fluxes to the DO variability at seasonal scale. The RMS of the climatological fluxes along a section at $12^{\circ} \mathrm{S}$ indicates that the maximum amplitude of the seasonal fluxes takes place near the oxycline and along the coast over the whole water column (Fig. 10). The relative importance of the physical processes against the biogeochemical processes varies across the OMZ. At the coast and near the oxycline, the annual variability of the biogeochemical processes reaches values almost half those of the variability in physical processes (Fig. 10c), as a consequence of the proximity to both the well-lit and highly productive part of the water column, and the high remineralization activity that occurs near the oxycline. Towards offshore and at depth, the relative importance of the variability of the biogeochemical processes reduces gradually. Near $\sim 300 \mathrm{~m}$ the variability of the biogeochemical processes is nearly one-fifth of the physical processes variability. Below $\sim 300 \mathrm{~m}$, and towards the lower part of the $\mathrm{OMZ}$ core and below, the physical processes variability is 1 order of magnitude larger. Consequently, the distribution of DO in the lower part of the OMZ is rather a function of advection/diffusion than a consequence of the biogeochemical processes, although DO consumption even at very low levels has the potential to generate local gradients and therefore induce advection. The spatial heterogeneity in the seasonal DO changes induced by the biogeochemistry and dynamics, as described above, appears as an ubiquitous feature in the OMZ. To illustrate this, we estimate the proportion of explained variance of the seasonal DO rate of change by the physical fluxes as

$$
\begin{gathered}
R_{\text {Phys. }}^{2}=(1-\operatorname{RMS}(\text { biogeochemical fluxes }) / \\
\operatorname{RMS}(\text { total fluxes })) \cdot 100 .
\end{gathered}
$$

Figure $11 \mathrm{a}$ and b present the results of $R_{\text {Phys. }}^{2}$ at 100 and $450 \mathrm{~m}$ depth, which evidences that the relative importance of the physical fluxes versus the biogeochemical fluxes in the seasonal DO variability increases with depth and is enhanced at the OMZ boundaries. However, the biogeochemical fluxes explain more than $50 \%$ of the variance in seasonal 


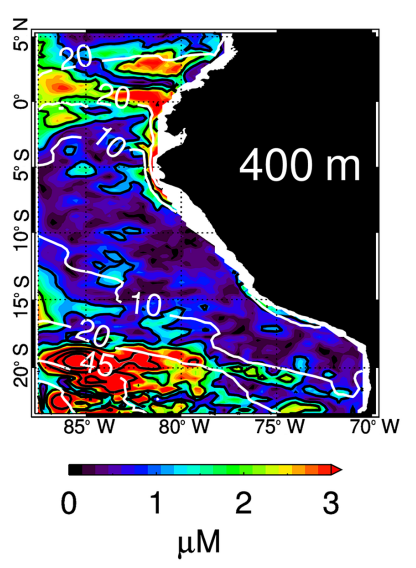

Figure 9. Annual DO harmonic amplitude at $400 \mathrm{~m}$ depth. White contours denote the 10,20 and $45 \mu \mathrm{M}$ mean oxygen isolines. Black contours denote the $1,2,4,6$ and $8 \mu \mathrm{M}$ levels.

DO change rate in a narrow $(\sim 200 \mathrm{~km}$ width) coastal fringe that extends more offshore to the north of the domain (around $8^{\circ} \mathrm{S}$; Fig. 11a) and vertically down to $300 \mathrm{~m}$ (Fig. 11c).

Based on the above analysis, it is clear that the coastal region (first $200-300 \mathrm{~km}$ from the coast) below the oxycline corresponds to a territory where the seasonal variability of biogeochemical and physical fluxes have a comparable magnitude, whereas outside this region, notably in the lower part of the OMZ core, the physical fluxes variability dominates over the biogeochemical fluxes variability at seasonal timescale. Hereafter we examine the possibility of two distinct regimes of OMZ dynamics at seasonal timescale: one associated with the upper OMZ (including coastal domain and meridional boundaries), and one associated with the deep OMZ. In the following we investigate the processes responsible for the DO flux.

\section{Seasonality of the $\mathrm{OMZ}$ ventilation}

It has been shown for the SEP that the DO content near the coast is set to a large extent from the transport of oxygendeficient waters from the equatorial current system, particularly the oxygen-depleted secondary southern subsurface countercurrent (Montes et al., 2014). Therefore, the seasonal variability of DO is likely to result in part from the seasonal variability of the different branches of the EUC in the far eastern Pacific. Local wind stress forcing (and its intraseasonal activity) has also a marked seasonal cycle off Peru (Dewitte et al., 2011) which may impact both the upwelling dynamics - through Ekman pumping/transport - and mixing. Some studies also argue that the DO exchange between the coastal domain and the OMZ takes place through the offshore transport of DO-poor waters by eddies (Czeschel et al., 2011), implying that the variability of such processes is set up by coastal processes that determine the nature of the DO source. As a first step, we investigate the mechanisms responsible for the seasonal variability in DO along the coast, which can be considered as the eastern boundary of the OMZ. This is aimed at providing material for the interpretation of the offshore DO flux variability.

\subsection{The coastal domain as the eastern boundary of the OMZ: variability and mechanisms}

We analyze the seasonal variability along the coast, at a section at $12^{\circ} \mathrm{S}$. Similar results are obtained for latitudes between 7 and $14^{\circ} \mathrm{S}$ (not shown), which corresponds to the latitude range where the Peru Undercurrent (PUC) is well defined. The results are also presented in terms of the first empirical orthogonal function (EOF) mode, in order to ease the interpretation of the variability, reduced as a spatial pattern modulated by a seasonal time series. It was verified in particular that the consideration of the first EOF mode of each term leads to an almost perfect closure of the DO budget (see below, Table 1). Figure 12 displays the first EOF mode of various climatological fields in a section at $12^{\circ} \mathrm{S}$ near the coast and from the oxycline ( $45 \mu \mathrm{M}$ isoline) to the depth of $300 \mathrm{~m}$. Figure 13 shows the principal components associated with the first EOF-mode patterns. The seasonal DO cycle is dominated by an annual component, with a peak centered in August (Fig. 13a), and the largest variability at the coast below the oxycline that extends offshore and downward, resulting in an elongated tongue below $100 \mathrm{~m}$ near $\sim 78^{\circ} \mathrm{W}$ (Fig. 12a). During the first quarter of the year, oxygen anomalies remain relatively stable (oxygen rate nearly zero, Fig. 13b) and negative due to a high production of organic matter in austral summer (cf. Fig. 1c of Gutiérrez et al., 2011) that stimulates a subsurface oxygen consumption associated with the degradation of this organic matter. DO anomalies start to increase during the second quarter, become positive in June and reach their maximum in August (Fig. 13a). The peak anomaly in austral winter could be understood in terms of the increased mixing (see Fig. 13a showing EKE peaking in July) associated with the increase in baroclinic instability due to the seasonal intensification of the PUC from June. Note that the pattern of the first EOF mode of the alongshore current coincides with the mean position of the PUC (see Fig. 12b), so that seasonal variations of the PUC can be interpreted in terms of the variations in the vertical shear of the coastal current system. Other processes that may explain the peak DO anomaly in austral winter include the reduced productivity and downwelling that peaks in June (Fig. 13c), associated with seasonal equatorial downwelling Kelvin wave.

The following investigates the tendency terms of the DO budget in order to quantitatively interpret the DO seasonal cycle near the coast. Given that the analysis is performed inside the $45 \mu \mathrm{M}$ isopleth, the biogeochemical flux term is largely dominated by the "sinks" terms (aerobic processes; 1 order of magnitude larger than "sources"), driven by organic matter remineralization and zooplankton respiratory 


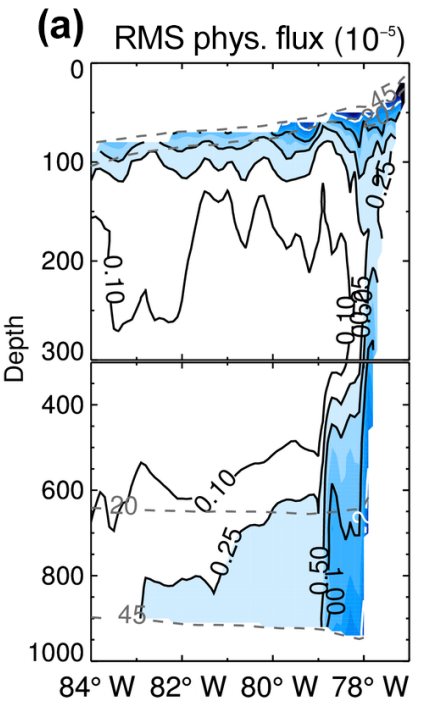

(b)

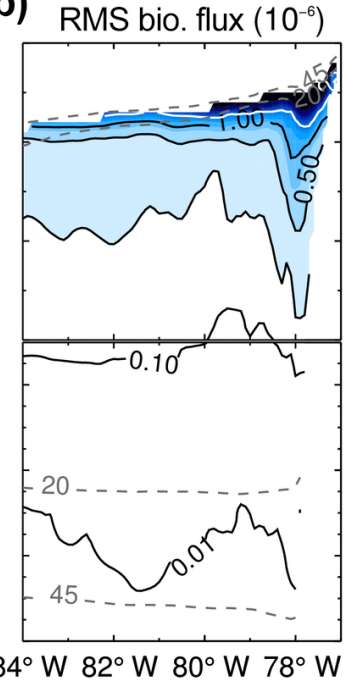

(c)

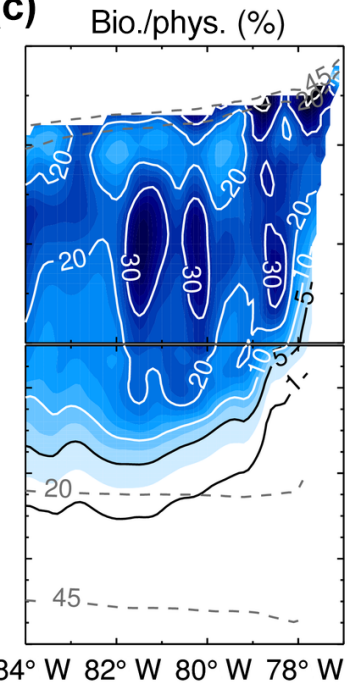

Figure 10. Root mean square of the seasonal cycle of (a) physical and (b) biogeochemical oxygen fluxes (in $10^{-5}$ and $10^{-6} \mu \mathrm{Ms}^{-1}$, respectively) for $\mathrm{CR} \mathrm{BIO}$ at $12^{\circ} \mathrm{S}$. (c) Ratio between the RMS of the biogeochemical fluxes and the physical fluxes, expressed as percentage. Dashed contours depict the 45 and $20 \mu \mathrm{M}$ mean oxygen values. Note the vertical scale change at $300 \mathrm{~m}$ depth. Land and the region outside the $45 \mu \mathrm{M}$ mean DO isopleth are masked in white.
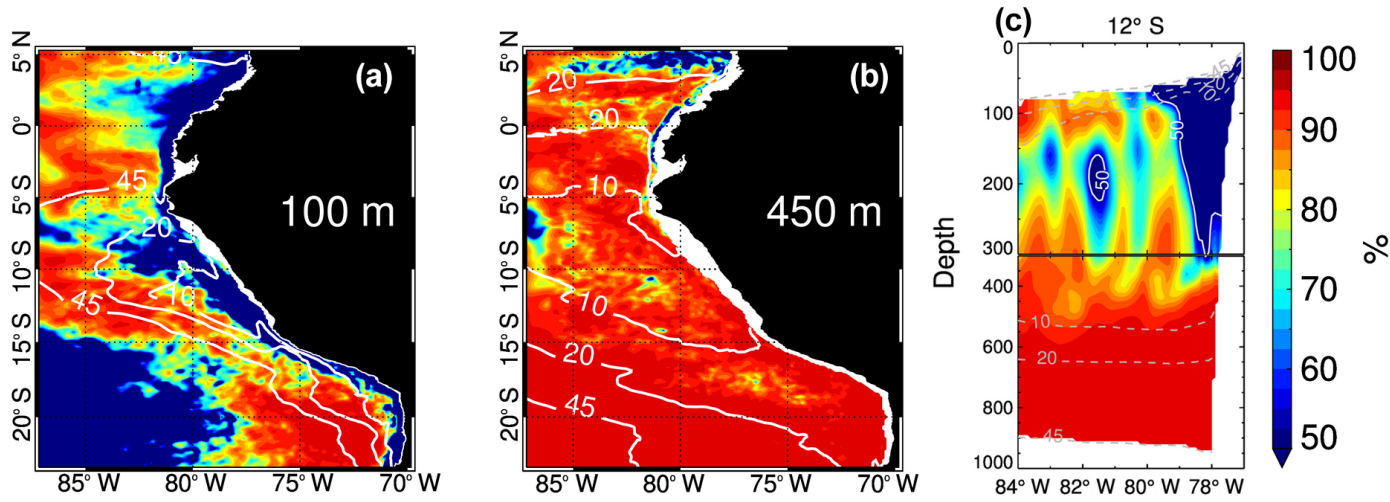

Figure 11. Percentage of the seasonal DO rate variance explained by the physical fluxes, at (a) 100 and (b) $450 \mathrm{~m}$ depth, and along a crossshore section at $12^{\circ} \mathrm{S}$. Solid white lines $(\mathbf{a}, \mathbf{b})$ and dashed gray lines (c) denote the 10, 20 and $45 \mu \mathrm{M}$ mean DO isopleths. Land and the region outside the $45 \mu \mathrm{M}$ mean DO isopleth are masked in white in (c).

metabolic terms (not shown). For clarity, the seasonal DO budget is presented synthetically, from the first EOF mode of the climatological advection, mixing (horizontal and vertical diffusion) and biogeochemical fluxes terms. Although this does not warranty a perfect closure, it eases the interpretation. Note that the residual resulting from the difference between the first EOF mode of the rate of DO changes and the summed-up contribution of all the other terms in Fig. 13b is rather weak, validating to some extent our approach (see also Table 1). First of all, we find that the largest amplitude of the mode patterns is found near the coast and inside the mean PUC core (Fig. 12d to g). During the first part of the year (January to May), positive advection anomalies are compensated by mixing (horizontal and vertical diffusion), and they maintain the rate of DO change relatively low (Fig. 13b; Table 1). Biogeochemical fluxes anomalies are positive during that period, associated with a positive anomaly of primary production in the well lit surface layers, implied by the high chlorophyll $a$ values (Fig. 13c). A positive oxygen anomaly is sustained by the advection terms and the biogeochemical terms and is balanced out by the mean advection of low DO waters carried by the PUC (Montes et al. 2010, 2014), generating the relatively stable oxygen values (oxygen rate nearly $0)$.

From May, the rate of DO changes increases concomitantly with EKE (Fig. 13a, b), followed 1 month later by mixing (horizontal and vertical diffusion), whereas advection and biogeochemical fluxes decrease. By June-July, the inten- 
Table 1. Austral summer (DJF mean) and winter (JJA mean) seasonal anomalies of the DO budget, averaged over the core of the Peru Undercurrent at $12^{\circ} \mathrm{S}$ (as depicted by the red contour in Fig. 12). The values for the seasonal cycle and the reconstructed first EOF mode (Figs. 12 and 13) are presented along with the difference between climatology and EOF. All values are in $10^{-6} \mu \mathrm{M} \mathrm{s}^{-1}$. Mixing here consists in the summed-up contribution of horizontal diffusion $\left(K_{h} \times \nabla^{2} \mathrm{O}_{2}\right)$ and vertical diffusivity $\left(\frac{\partial}{\partial z}\left(K_{Z} \frac{\partial \mathrm{O}_{2}}{\partial z}\right)\right)$.

\begin{tabular}{lrr|rr|rr}
\hline & \multicolumn{2}{c|}{ Climatology } & \multicolumn{2}{c|}{ EOF } & \multicolumn{2}{c}{ Difference } \\
\cline { 2 - 7 } & Summer & Winter & Summer & Winter & Summer & Winter \\
\hline $\mathrm{\partial O}_{2} / \partial t$ & 1.10 & -2.74 & 1.30 & -2.67 & -0.20 & -0.07 \\
$\mathrm{Adv}$ & 0.61 & -9.38 & 0.85 & -9.30 & -0.24 & -0.08 \\
$\mathrm{Mixing}$ & -0.42 & 7.99 & -0.35 & 7.99 & -0.07 & 0.00 \\
Biogeochemical flux & 0.91 & -1.35 & 1.00 & -1.35 & -0.09 & 0.00 \\
\hline
\end{tabular}

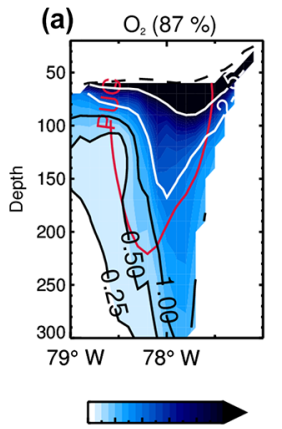

012345 $\mu \mathrm{M}$
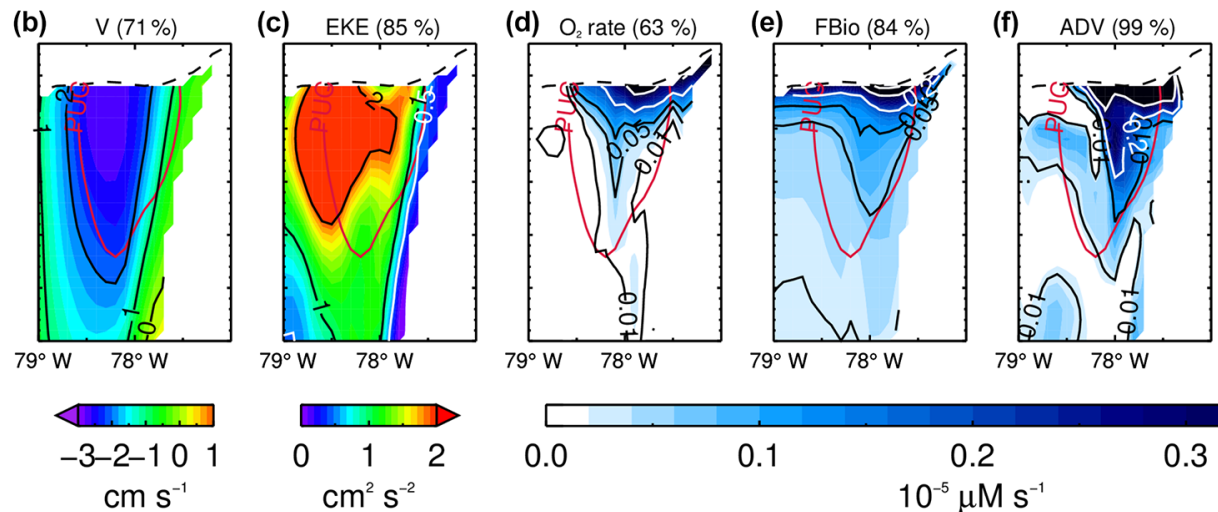

(g) ${ }_{\mathrm{Hmix}}+\mathrm{V}_{\operatorname{mix}}(98 \%)$

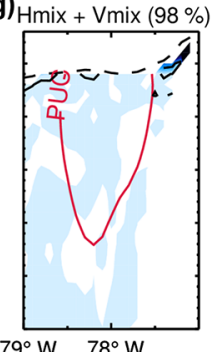

0.0

0.1

$10^{-5} \mu \mathrm{M} \mathrm{s}^{-1}$
0.3

0.4

Figure 12. First EOF-mode pattern of (a) DO, (b) alongshore currents component, (c) eddy kinetic energy, (d) oxygen rate, (e) biogeochemical flux, (f) advective terms (sum of horizontal and vertical components) and (g) mixing terms (sum of horizontal and vertical components). Percentage of explained variance by each EOF-mode pattern is indicated in parentheses on top of each panel. The red contour denotes the mean position of the Peru Undercurrent core, defined here as alongshore southward current exceeding $4 \mathrm{~cm} \mathrm{~s}^{-1}$. The black dashed contour denotes the mean DO $45 \mu \mathrm{M}$ isopleth. Land and the region outside the $45 \mu \mathrm{M}$ mean DO isopleth are masked in white. The EOF-mode patterns were multiplied by the RMS of the principal component (PC) time series. Multiplying the EOF pattern by the PC time series plotted in Fig. 13 yields the contribution of the first EOF mode to the original field, in dimensionalized units (i.e., $\mu \mathrm{M} \mathrm{s}^{-1}$ for the tendency terms).

sification in alongshore winds (Fig. 13c) starts to propel the coastal upwelling, which has two compensating effects: on one hand, it triggers photosynthesis in the lit surface layers (DO rate turns to positive values); on the other hand, it uplifts low-oxygen waters from the OMZ. The intraseasonal wind activity also starts to increase at that time (cf. Fig. 13c; see also Dewitte et al., 2011), which favors mixing and the downward intrusion of positive DO anomalies (note the deepening of the mixed layer in Fig. 13c). The overall effect is an increase in DO, which leads to a peak anomaly in August. At that time, the DO rate drops sharply due to the strong subsurface DO consumption (Table 1) associated with aerobic remineralization of organic matter produced earlier in the season (DO rate moves sharply to negative values) and the high mixing that brings DO-depleted waters from the subsurface into the deepened mixed layer. Note that this is consistent with the decrease in surface chlorophyll $a$ (Fig. 13c) and the interpretation proposed by Echevin et al. (2008) to explain the austral summer minimum in surface chlorophyll $a$ observed off central Peru.

This change to oxygen-poor conditions combines with the natural decrease in oxygen production towards the end of the upwelling season and coincides with a restratification of the water column, which restricts the oxygenated waters near the surface (Echevin et al., 2008). This altogether contributes to maintain a negative DO rate inside the coastal OMZ, despite the increase in anomalous DO flux from the advective terms and (later on) biogeochemical processes towards the end of the year. As a result, oxygen returns to low values towards the end of the year.

\subsection{Offshore flux}

While the coastal OMZ variability is heavily constrained by the environmental forcings - coastal upwelling, coastal current system and local wind - due to the shallow oxycline there, the offshore OMZ, as embedded in the shadow zone of the thermohaline circulation, is somewhat insensitive 
to direct local forcing and rather experiences remote influence in the form of westward-propagating mesoscale eddies (Chaigneau et al., 2009) and ETRW (Ramos et al., 2008; Dewitte et al., 2008). The influence of westward-propagating mesoscale eddies on the OMZ translates as the transfer of coastal water properties towards the open ocean (DO included), while these properties are altered during transport due to physical/biogeochemical interactions (Stramma et al., 2014; Karstensen et al., 2015). Towards the end of their lifetime, hydrographic and biogeochemical anomalies carried by eddies are redistributed in the ocean (Brandt et al., 2015), linking the coast and the open ocean. Although most eddy genesis takes place near the coast and seasonal ETRW have a coastally forced component, we expect different characteristics of the seasonal variability in DO between the coast and the open ocean, given that oxygen demand will change from one region to the other. We also distinguish the mean DO flux associated with the annual component of the circulation that represents the transport in DO associated with seasonal changes in the large-scale circulation and the annual variability of the DO eddy flux that corresponds to the annual changes in the transport due to eddies. These two quantities are diagnosed at $12^{\circ} \mathrm{S}$ (Figs. 14 and 15). The DO has been normalized by its climatological variability in order to emphasize variability patterns where DO is low.

\subsubsection{Mean seasonal flux}

We first document the mean DO flux associated with the annual component of the circulation. It consists in the mean of the cross-product of the annual harmonics of the climatological velocity and DO (Fig. 14a). The results indicate that the amplitude of the annual DO flux is maximum near the coast and below $\sim 400 \mathrm{~m}$ and it tends to be orientated westwarddownward, following approximately the trajectories of theoretical WKB paths for the annual period Rossby wave. Note that this is consistent with the westward-propagating pattern of DO below $400 \mathrm{~m}$ evidenced earlier (Fig. 8). As a consistency check, we also estimated the annual energy flux vector in the $(x, z)$ plane associated with a long extratropical Rossby wave; that is $\left(\left\langle p^{1 \mathrm{yr}} \times u^{1 \mathrm{yr}}\right\rangle,\left\langle p^{1 \mathrm{yr}} \times w^{1 \mathrm{yr}}\right\rangle\right)$ where the superscript denotes the annual harmonics and the bracket the temporal average (Fig. 14b). The flux vector indicates vertical propagation of energy at the annual period and the pattern of maximum flux coincides approximately with the region of maximum amplitude of the mean seasonal DO flux. This suggests that the annual ETRW are influential on the DO flux below $\sim 400 \mathrm{~m}$. This is interpreted as resulting from the advection of DO by the ETRW since biogeochemical fluxes have much less influence on the DO rate of change below $400 \mathrm{~m}$ (Fig. 10c) and the amplitude of the annual cycle of climatological DO eddy flux has a much reduced amplitude below that depth (Fig. 15a), suggesting a small contribution of horizontal and vertical diffusion to the DO budget. Note that the DO (Fig. 15a) was normalized prior to compute the DO eddy

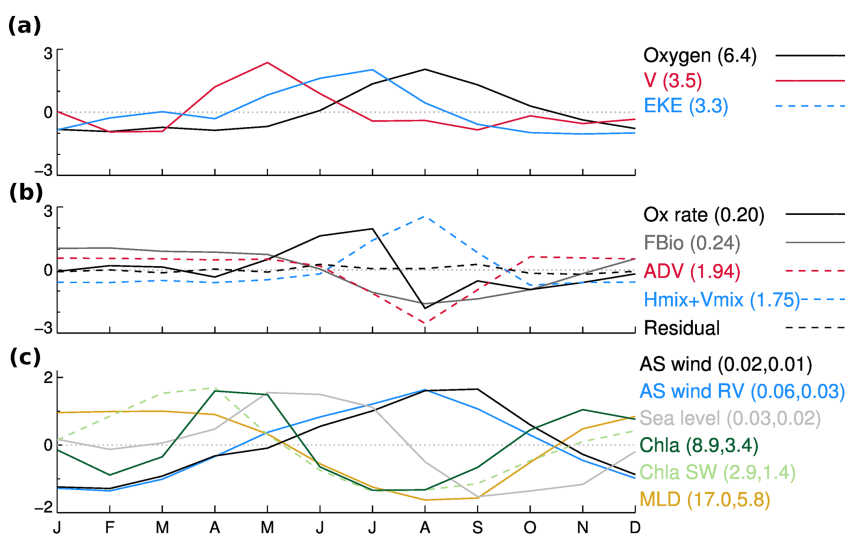

Figure 13. (a, b) Non-dimensional principal components (PCs) associated with the EOF patterns in Fig. 12. Multiplying the principal component by the associated EOF pattern (from Fig. 12) yields a first EOF-mode reconstruction of the original field. RMS values of the principal components are indicated in parenthesis (corresponding units as in Fig. 12). The residual corresponds to the difference between the rate of DO change and the sum of all the terms of the right-hand side of Eq. (1) in terms of the normalized PC time series. The weak residual indicates that the seasonal DO budget can be interpreted from the EOF decomposition. The EOF decomposition was performed over the climatological (mean seasonal cycle) fields. (c) Normalized seasonal cycle of coastal alongshore wind (AS wind) and coastal alongshore wind running variance (variance over a 30-day running window) at $12^{\circ} \mathrm{S}$, sea level at the coast at $12^{\circ} \mathrm{S}$, surface chlorophyll $a$ from CR BIO $(\mathrm{Chl} a)$ and from SeaWiFS (Chl $a \mathrm{SW}$ ) averaged over a coastal band of $2^{\circ}$ width at $12^{\circ} \mathrm{S}$, and mixed layer depth (MLD) at the coast at $12^{\circ} \mathrm{S}$. Mean and RMS used to normalize each time series, are indicated in parenthesis. Original seasonal cycle is found by multiplying the normalized series by its RMS and then adding the mean. Original units are $\mathrm{N} \mathrm{m}^{-2}, \mathrm{~m}, \mathrm{mg} \mathrm{m}^{-3}$ and $\mathrm{m}$, respectively.

flux, so it is possible to compare to Fig. 14a, and therefore contrast the flux associated with the annual ETRW against the annual DO eddy flux. It was verified that the vertical structure variability of the annual DO flux described above for the section of $12^{\circ} \mathrm{S}$ is comparable at other latitudes within the OMZ. In particular, the annual DO flux tends to remain homogeneous along trajectories mimicking the energy paths of the ETRW at the annual period when the slope becomes steeper to the south (not shown).

\subsubsection{Seasonal eddy flux}

As previously described, the annual amplitude of the climatological DO eddy flux is the largest in the upper $400 \mathrm{~m}$ near the coast at $12^{\circ} \mathrm{S}$ consistently with the high EKE in this region. Since EKE is large along the coast of Peru, exchange of DO induced by eddies could be expected at all latitudes, with a direction that depends on the sign of the DO gradient at the coast. Figure 16 presents the annual harmonic of the climatological DO eddy flux along the coast and averaged in 


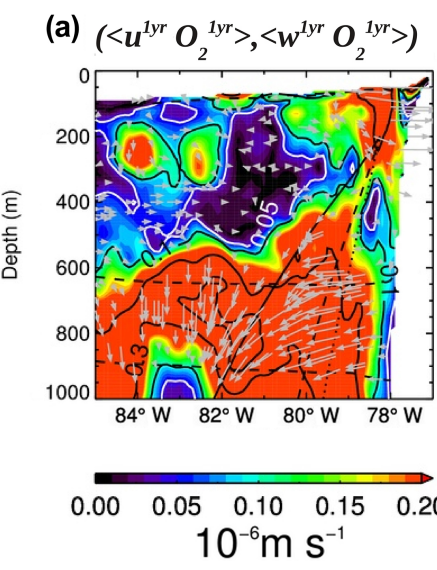

(b)

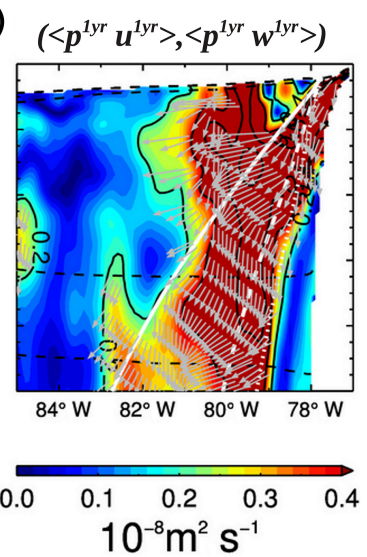

Figure 14. (a) Norm of the annual DO flux vector (i.e., $\sqrt{\left.\left(\left\langle u^{1 \mathrm{yr}} \times \mathrm{O}_{2}^{1 \mathrm{yr}}\right\rangle\right)^{2}+\left(\left\langle w^{1 \mathrm{yr}} \times \mathrm{O}_{2}^{1 \mathrm{yr}}\right\rangle\right)^{2}\right)}$ for a cross-shore section at $12^{\circ} \mathrm{S}$. Arrows indicate the vector direction $\left(\right.$ i.e., $\left.\left[\left\langle u^{1 \mathrm{yr}} \times \mathrm{O}_{2}^{1 \mathrm{yr}}\right\rangle,\left\langle w^{1 \mathrm{yr}} \times \mathrm{O}_{2}^{1 \mathrm{yr}}\right\rangle\right]\right)$. The $\mathrm{DO}$ signal was normalized by its root mean square value before computing the annual harmonic in order to emphasize the flux patterns where DO concentration is very low. (b) Norm of the annual energy flux vector (i.e., $\left.\sqrt{\left(\left\langle p^{1 \mathrm{yr}} \times u^{1 \mathrm{yr}}\right\rangle\right)^{2}+\left(\left\langle p^{1 \mathrm{yr}} \times w^{1 \mathrm{yr}}\right\rangle\right)^{2}}\right)$. Arrows inside the 0.2 contour indicate the vector direction (i.e., $\left.\left[\left\langle p^{1 \mathrm{yr}} \times u^{1 \mathrm{yr}}\right\rangle,\left\langle p^{1 \mathrm{yr}} \times w^{1 \mathrm{yr}}\right\rangle\right]\right)$. Some theoretical WKB trajectories (1-year period) originating from near the coast at the surface are drawn for phase speed values of a first (full), second (dashed) and third (dotted) baroclinic modes. The range of phase speed values (modes 1-3) is obtained from a vertical mode decomposition of the mean model stratification. Dashed black contours indicate the 45 and $20 \mu \mathrm{M}$ mean DO isopleths. Land and the region outside the $45 \mu \mathrm{M}$ mean DO isopleth are masked in white.

a coastal fringe distant $1^{\circ}$ from the coast and $2^{\circ}$ width. The maximum amplitude - reaching $\sim 1 \mathrm{~cm} \mathrm{~s}^{-1} \mu \mathrm{M}$ - is concentrated in the upper oxycline (Fig. 16a) with a peak during austral winter. The peak season is also confirmed by the EOF analysis of the climatological DO eddy flux (not shown). Despite the relative large meridional variability in the amplitude, the mean vertical structure of the DO eddy flux consists in an approximate exponentially decaying profile with depth, with a decay scale of $\sim 90 \mathrm{~m}$ (Fig. 16b) so that at $300 \mathrm{~m}$ the seasonal DO eddy flux is on average only $19 \%$ of that at $100 \mathrm{~m}$ along the coast. Figure 16a also reveals that the annual DO eddy flux is larger towards the northern rim of the domain and extends deeper than towards the south. The high values are increasingly confined close to the surface towards the southern part of the domain, in comparison to the northern part, although the vertical attenuation displays a similar scale.

\subsection{Meridional boundaries}

Here, our objective is to document the seasonality of the DO eddy flux. As a first step, we estimate the distribution of mean

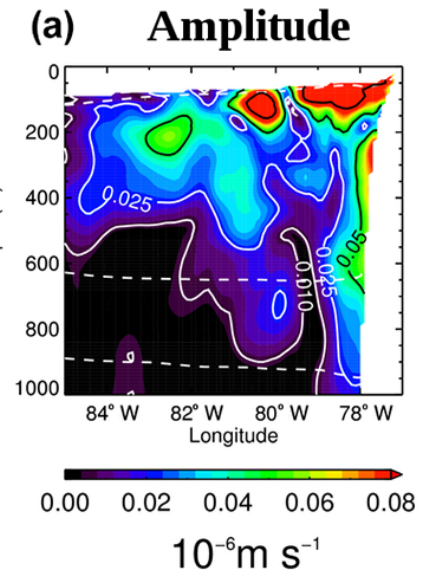

(b) Phase

Figure 15. Zonal section of the annual harmonic of the module of the seasonal DO eddy-flux vector $\left.\left(\overline{\left\langle u^{\prime} \times \mathrm{O}_{2}^{\prime}\right.}\right\rangle, \overline{\left\langle w^{\prime} \times \mathrm{O}_{2}^{\prime}\right\rangle}\right)$ at $12^{\circ} \mathrm{S}$. (a) Amplitude of the harmonic and (b) phase of the annual maximum (in months). Dashed white contours indicate the 45 and $20 \mu \mathrm{M}$ mean DO isopleths. DO was normalized by its RMS prior to carrying out analysis. Land and the region outside the $45 \mu \mathrm{M}$ mean DO isopleth are masked in white.

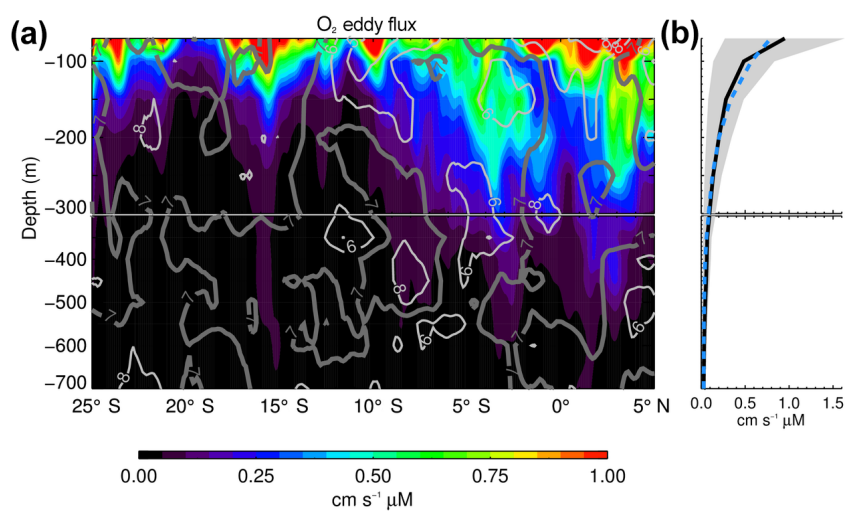

Figure 16. (a) Amplitude (color shading) and phase (months, gray contours) of the annual harmonic of the climatological DO eddy flux along the coast. The climatology of DO eddy flux was averaged over a coastal fringe of $2^{\circ}$ width, starting from $1^{\circ}$ from the coast. (b) Meridional average vertical profile (black line), \pm RMS (gray shading). An exponential model fitted to the average vertical profile (dashed blue line) yields a vertical decay scale of $\sim 90 \mathrm{~m}$.

DO eddy flux in order to identify the regions where its magnitude is large and thus where it is likely to vary seasonally with a significant amplitude.

\subsubsection{Mean seasonal flux}

The horizontal distribution of mean DO eddy flux displays the highest values at the boundaries of the OMZ core (Fig. 17) and adjacent to the $45 \mu \mathrm{M}$ isopleth. Towards the inner OMZ, the mean DO eddy-flux values decrease notoriously, with a factor of nearly 10 between the interior and 

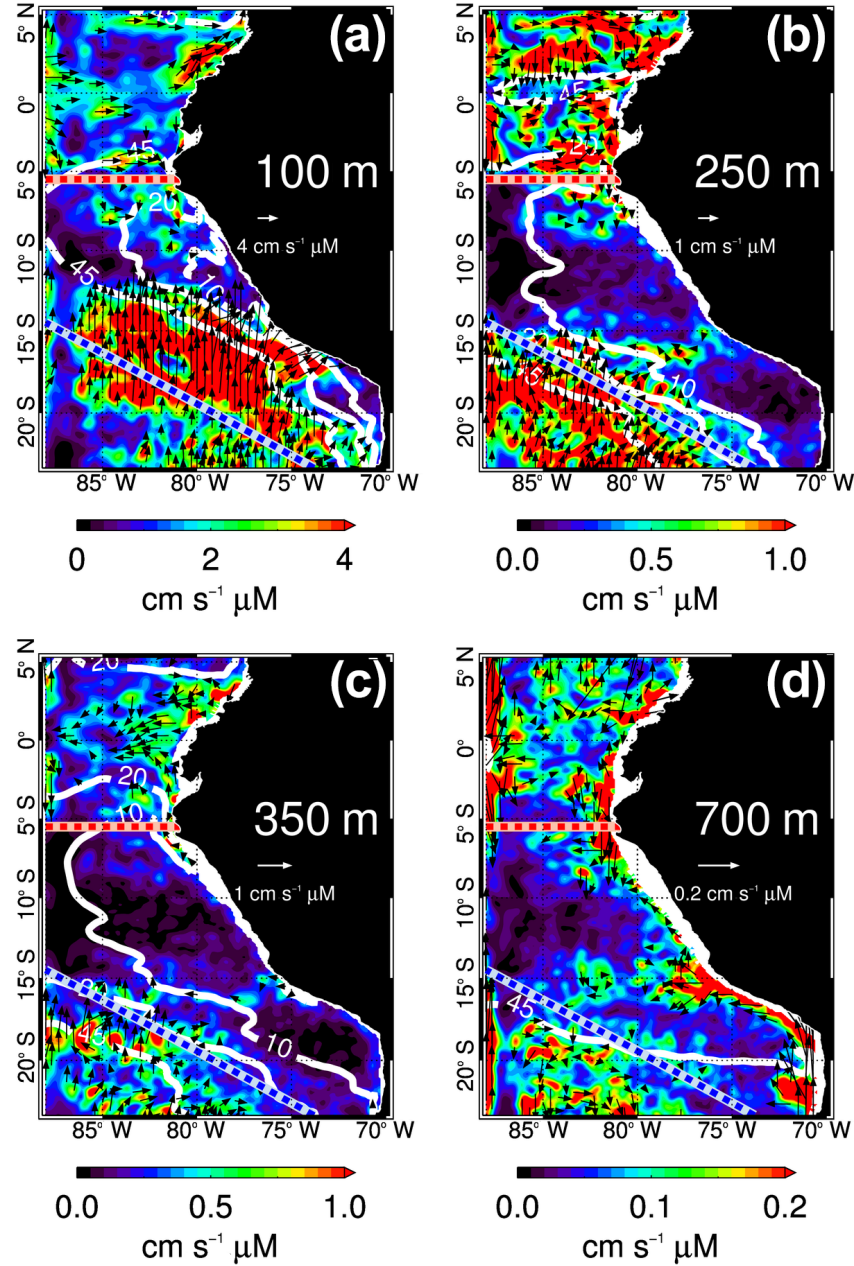

Figure 17. Module of the mean DO eddy-flux vector $\left(\left\langle u^{\prime} \times \mathrm{O}_{2}^{\prime}\right\rangle,\left\langle v^{\prime} \times \mathrm{O}_{2}^{\prime}\right\rangle\right)$ at (a) $100 \mathrm{~m}$, (b) $250 \mathrm{~m}$, (c) $350 \mathrm{~m}$ and (d) $700 \mathrm{~m}$ depth. Arrows displayed only for values above the central value in each color bar denote the vector direction and strength. White contours correspond to the 45, 20 and $10 \mu \mathrm{M}$ mean DO values. Red and blue lines denote the position of vertical sections.

exterior of the $10 \mu \mathrm{M}$ contour. In agreement with the observations reported in the previous section, the mean DO eddy flux decreases sharply with depth (approximately 1 order of magnitude between 100 and $700 \mathrm{~m}$ ), with the highest values concentrated near the oxycline, as expected from the increasing oxygen concentration in this part of the OMZ. In this sense, the pattern of DO eddy flux around the depth of the oxycline encloses a region of high variability (not shown).

To gain further insight with respect to the vertical structure of the DO eddy flux and at the same time diagnose the role of the mesoscale activity at the boundaries of the OMZ, we compute the mean DO eddy flux across the two sections that correspond to the northern and southern limits of the OMZ (depicted in Fig. 18). These limits are defined based on Fig. 17 and are located in the provinces of high amplitude of the mean DO eddy flux.

The DO eddy flux across each of the northern and southern boundaries was computed by averaging the product of the fluctuating velocity component normal to the boundary in the horizontal directions and the fluctuating DO concentration component, thereby obtaining horizontal eddy fluxes.

As observed in Fig. 17, the highest values for both northern and southern boundary sections are found between the oxycline and the lower OMZ core limit (Fig. 18), being almost 1 order of magnitude smaller at greater depths (Fig. 18c). These high values, located between $\sim 100$ and $300 \mathrm{~m}$, are followed by a sharp decrease (average decrease of $1.5 \mathrm{~cm} \mathrm{~s}^{-1} \mu \mathrm{M}$ in $100 \mathrm{~m}$ ). At the range of depths between 100 and $300 \mathrm{~m}$, the DO eddy flux displays higher values at the southern boundary (nearly twice as large) when compared with the northern boundary. This relationship is less clear when analyzing the lower part of the OMZ. At both meridional boundaries, the mean DO eddy flux in the upper part of the OMZ is nearly 1 order of magnitude larger than in the lower part.

\subsubsection{Seasonal eddy flux}

We now document the seasonal variability of the DO eddy flux across the OMZ boundaries analyzed above (Fig. 18). An EOF analysis of the mean seasonal cycle of the DO eddy flux is performed at the boundary sections previously defined. Figure 19 presents the first EOF-mode patterns along with the associated time series. In order to estimate the uncertainty associated with the location of the OMZ boundaries, we repeated this analysis for 12 nearby sections parallel to the boundaries and spaced by $\sim 20 \mathrm{~km}$. This leads to an estimated error (standard deviation across the different sections) of the DO eddy flux. The error is represented as a colored shading in Fig. 19b, d, e. At both locations, the first EOF accounts for a well-defined seasonal cycle. At the northern boundary (Fig. 19a), the seasonal cycle of the DO eddy flux peaks in austral winter, in phase with the DO changes along the coast (Fig. 16). Note that the seasonal cycle is in phase with that of the intraseasonal activity of the horizontal currents normal to the section, which was estimated the same way as the climatological eddy flux (see red line in Fig. 19b), supporting the idea that the climatological DO eddy flux results from anomalous advection. The amplitude of the mode pattern is maximum at the oxycline with DO between 20 and $45 \mu \mathrm{M}$ and presents a sharp decrease below the OMZ core depth (Fig. 19a). This sharp decrease is evidenced by the mean vertical profile of the DO eddy-flux seasonal variability estimated as the RMS across the section of the EOF-mode pattern (Fig. 19e). The vertical structure of the DO eddy-flux variability indicates that there is a difference of nearly 1 order of magnitude between 100 and $300 \mathrm{~m}$ depth. From that depth on, the DO eddy-flux variability decreases linearly. 

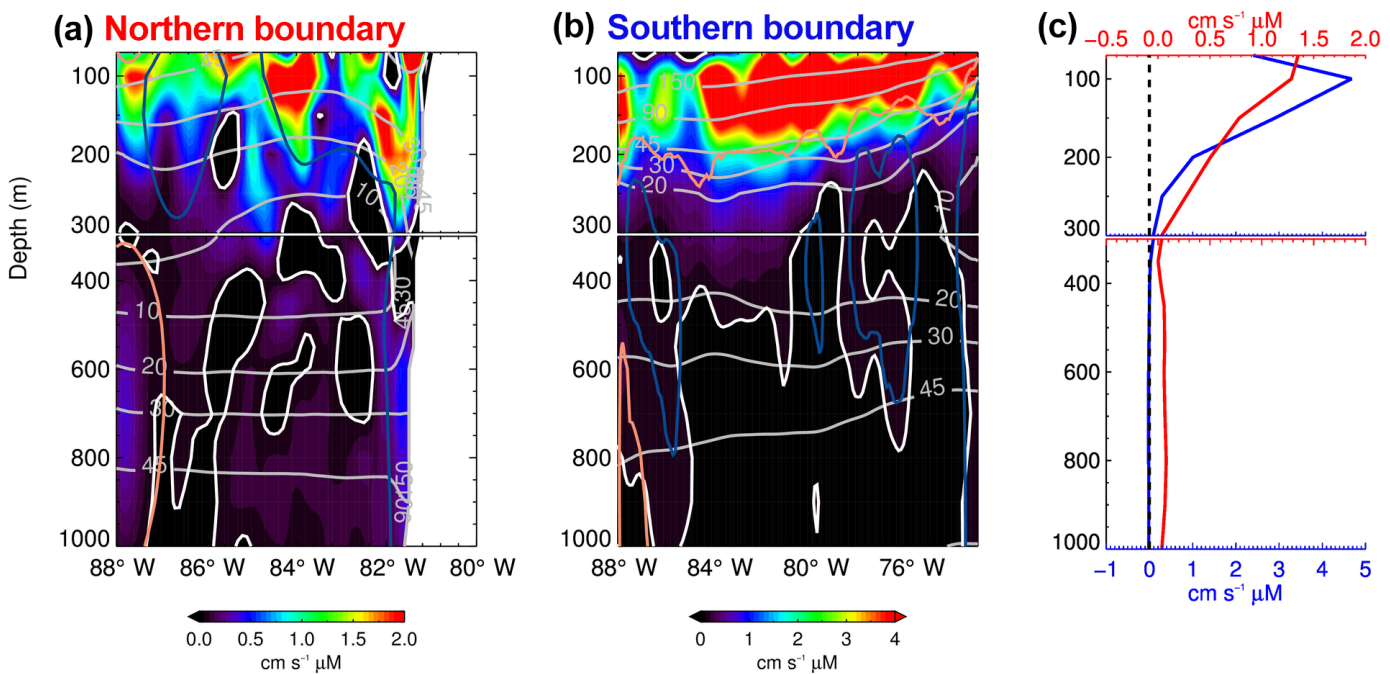

Figure 18. (a) Mean DO eddy flux normal to the section denoted by the red line in Fig. 17. (b) Mean DO eddy flux normal to the section denoted by the blue line in Fig. 17. (c) Horizontal mean of (a) and (b) (red and blue lines, respectively). Gray contours denote mean DO concentrations, and light red/blue contours correspond to positive/negative values of mean currents normal to the section $\left(1.0 /-1.0 \mathrm{~cm} \mathrm{~s} \mathrm{~s}^{-1}\right.$ in a and $0.4 /-0.2 \mathrm{~cm} \mathrm{~s}^{-1}$ in $\left.\mathbf{b}\right)$. White contour denotes the 0 value. The sign convention was chosen so that a positive horizontal flux indicates transport towards the interior of the OMZ.

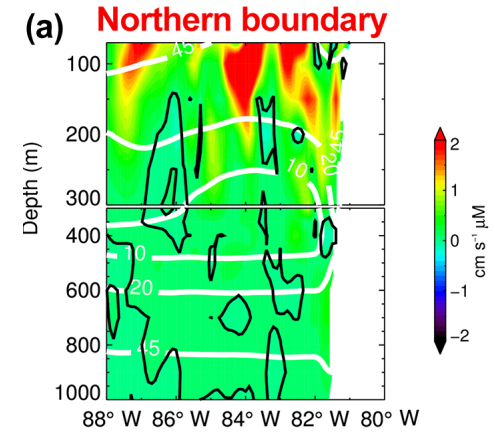

(b)

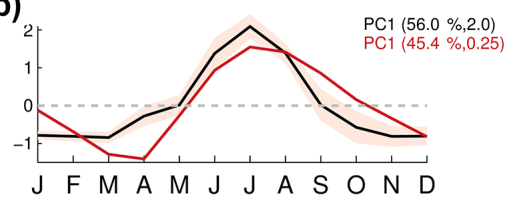

(c)

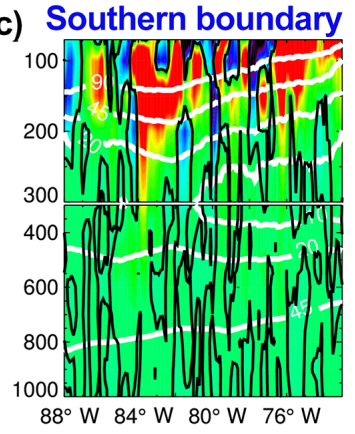

(d)

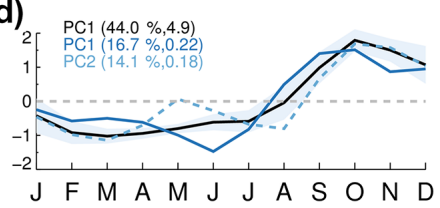

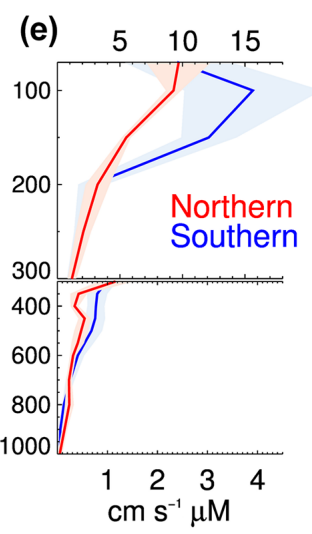

Figure 19. (a) First EOF mode of the seasonal cycle of the DO eddy flux normal to the section depicted in Fig. 17 by the dashed red line (northern boundary). (b) Principal component (PC) time series associated with the first EOF mode (black line). The red line in (b) corresponds to the PC time series associated with the first EOF mode of the seasonal cycle of the 30-day running variance of intraseasonal currents normal to the section. (c) First EOF mode of the seasonal cycle of the DO eddy flux normal to the oblique section depicted in Fig. 17 by the dashed blue line (southern boundary). (d) PC time series associated with the first EOF mode (black line). The blue curves (full and dashed lines) in (d) correspond to the PC time series associated with the first and second EOF modes of the seasonal cycle of the 30-day running variance of the intraseasonal currents normal to the section (computed as in b). Percentage of explained variance and RMS value are indicated in parentheses in the panels (b) and (d) (in $\mathrm{cm} \mathrm{s}^{-1} \mu \mathrm{M}$ and $\mathrm{cm} \mathrm{s}^{-1}$ for DO eddy flux and currents, respectively). White contours in (a) and (c) denote mean DO concentration values in $\mu \mathrm{M}$. (e) RMS of the spatial patterns (a) and (c), computed along the horizontal direction. Note the scale leap at $300 \mathrm{~m}$. Red/blue shading in (b), (d) and (e) represents an estimate of the error associated with slight changes in the location of the boundaries, i.e., when the EOF is performed over a section that is located at a distance from the original section (cf. Fig. 17) compromised between $\pm 120 \mathrm{~km}$ (see text). The error corresponds to the standard deviation among $12 \mathrm{PC}$ time series (for $\mathbf{b}$ and $\mathbf{d}$ ) and EOF patterns (for $\mathbf{e}$ ). 
In contrast with the northern boundary, the seasonal variability at the southern boundary peaks during austral spring (Fig. 19d), in phase with the intraseasonal activity of the horizontal currents normal to the section. The amplitude of the seasonal cycle is the largest around the depth of the oxycline and remains high down to the vicinity of the OMZ core upper limit (Fig. 19c). Below the depth of the OMZ core, the amplitude of the EOF mode decreases sharply ( $\sim 1$ order of magnitude in $100 \mathrm{~m}$; Fig. 19c). This is evidenced by the profile of the DO eddy-flux seasonal variability, estimated in the same manner as for the northern boundary (Fig. 19e). This profile shares some characteristics with its counterpart at the northern boundary, meaning a sharp decrease between the oxycline and the OMZ core depths, suffering a reduction of nearly $90 \%$ (Fig. 19e). In contrast, the variability along the southern boundary is $\sim 70 \%$ larger than along the northern boundary. At both boundaries, the zonal wavelength of the seasonal DO eddy-flux variability along the boundary is estimated to be in the order of $\sim 10^{2} \mathrm{~km}$, a scale that falls within the range of observed eddies diameter (Chaigneau and Pizarro, 2005), which indicates that locally there can be an injection or removal of DO across the boundary on average over a season. The mean DO eddy flux across the boundaries is nevertheless positive.

\section{Discussion}

We now discuss some limitations and implications of our results. While the model realistically simulates the main characteristics of the OMZ (position, intensity, average volume and seasonal variations), it still presents biases that could be influential on our results. In particular, and since the coastal domain is viewed here as a boundary of the OMZ, it is important to have a realistic mean DO concentration there. Compared to CARS, the simulated suboxic volume is, however, underestimated by $\sim 6 \%$, and $85 \%$ of this error can be attributed to the coastal domain (fringe of $3^{\circ}$ from the coast). This bias could be due to several factors. Montes et al. (2014) observed variations of the suboxic volume in the order of $5 \%$ when contrasting two simulations that used different oceanic open boundary conditions, which indicates a sensibility of the simulated OMZ to the physical parameters and to the representation of the equatorial current system. This bias could also be partly due to coastal sediments processes (DO demanding processes) that are not represented in our simulation. Using a similar configuration to the one used in the present study on the Namibian OMZ, Gutknecht et al. (2013a) observed that the differences between the simulated OMZ volume and CARS increased towards the shelf, which could be related to the exclusion of the DO demand from the sediments in the model. The role of benthic processes in constraining the DO demand has been studied in the northern California current system (Bianucci et al., 2012; Siedlecki et al., 2015), indicating that locally such processes might be essential to explain the hypoxic conditions. The inclusion of a sediment module in the current model setting is planned for future work to address this issue.

Another process that could contribute to the underestimation of the suboxic volume in the simulation is the higher mesoscale activity in the model compared to the observations (Fig. 1), which could in turn induce a higher ventilation of the $\mathrm{OMZ}$ in the simulation.

Besides other likely sources of biases related to an imperfect model setting (e.g., use of relatively low-resolution atmospheric forcings near the coast, absence of air/sea coupling at mesoscale, absence of coupling with benthic oxygen demand or consideration of $\mathrm{N}_{2}$ fixation), another inherent limitation of our study is related with the difficulty in validating some aspects of the eddy field, in particular its vertical structure. This might be overcome in the future as the Argo coverage increases (cf. TPOS2020).

With the limitations of our regional modeling approach in mind, it is worthwhile to discuss some implications of our results. While previous studies have mostly focused on the role of the mean DO eddy flux in shaping the OMZ (Resplandy et al., 2012; Brandt et al., 2015; Bettencourt et al., 2015), we have documented here how the seasonal DO changes inside the OMZ are essentially controlled by the DO eddy flux at the OMZ limits, which means that the seasonality of the OMZ can be interpreted as resulting from a modulation of the mesoscale activity at seasonal timescales. We infer that the seasonality of the DO eddy flux is regulated by different physical processes depending on the region. At the coast, there is a constructive coupling between eddies resulting from the instability of the PUC peaking in austral winter and the enhanced DO along the coast resulting from an increased horizontal and vertical diffusion at the same season.

At the northern part of the OMZ, the DO eddy flux is related to the strong EKE around $5^{\circ} \mathrm{S}$ that peaks in austral winter. Despite the fact that the northern OMZ is embedded in the equatorial wave guide, it can be ruled out that the seasonal cycle in DO eddy flux is strongly linked to the intraseasonal long equatorial waves since the intraseasonal Kelvin wave activity tends to peak in austral summer (Illig et al., 2014). The boundary forcing sensitivity model experiments of Echevin et al. (2011) also suggest that the enhanced mesoscale activity observed off northern Peru during winter would be related to internal variability or local wind stress rather than being connected to the equatorial Kelvin wave activity. Whether or not the strong EKE found there results from the instability of the coastal currents system or of the EUC and the South Equatorial Current would need to be explored.

Regarding the southern boundary, it is interesting to note that the DO eddy-flux peaks in austral spring, 3 months later than at the northern boundary. A possible mechanism driving the local variability observed at the southern section is the generation of local baroclinic instability and vorticity input from wind stress curl as observed for the Califor- 


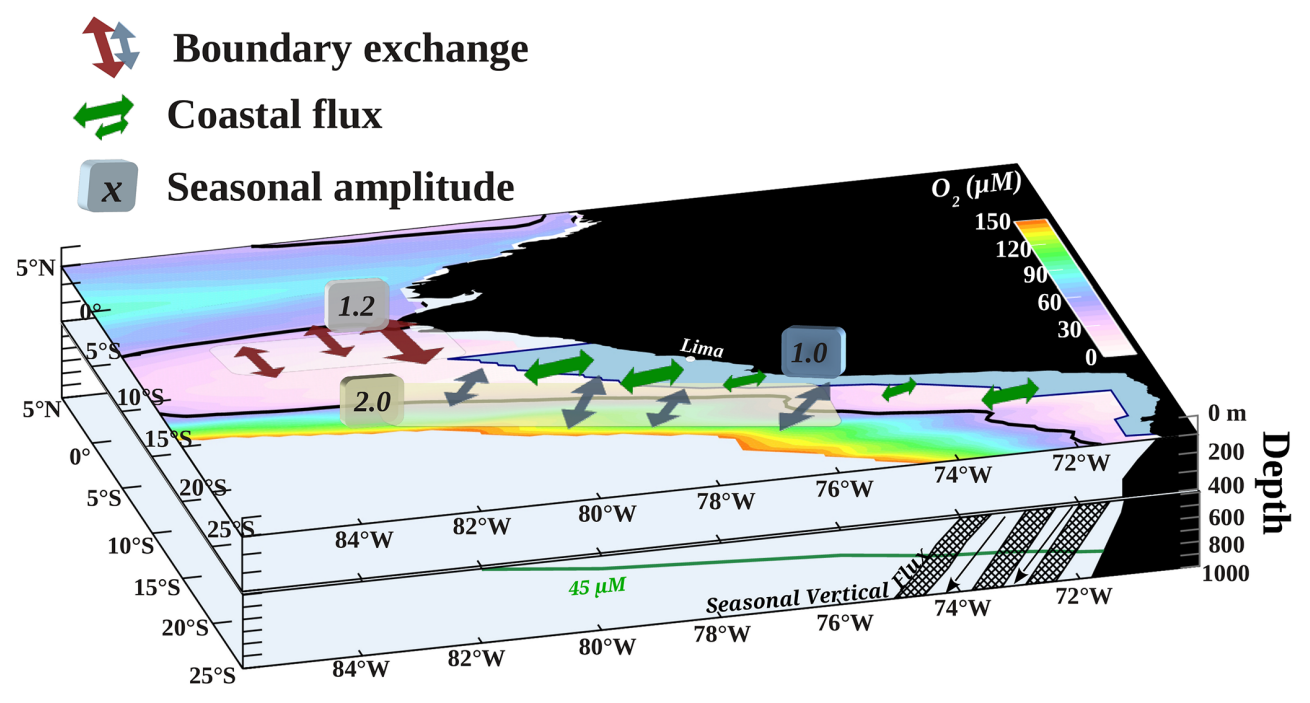

Figure 20. Schematic of the main processes driving the seasonal variability in the SEP OMZ: the DO eddy flux through the north-south boundaries and the DO flux that takes place at the coastal boundary of the OMZ. The coastal band limits are defined by the light blue shading adjacent to the coast. A scale of the seasonal amplitude of the eddy-driven DO flux at each OMZ boundary is indicated (units in $\mathrm{cm} \mathrm{s}{ }^{-1} \mu \mathrm{M}$ ). The mean DO concentration (color shading) and the position of the $45 \mu \mathrm{M}$ isopleth (thick black contour) at $100 \mathrm{~m}$ depth are also represented. The vertical/offshore DO flux induced by the propagation of the annual ETRW across the $45 \mu \mathrm{M}$ isopleth at $25^{\circ} \mathrm{S}$ is represented in the bottom panel.

nia system (Kelly et al., 1998). The southern section lies within the northeastern rim of the southeast Pacific anticyclone, and the peak in the seasonal DO eddy flux coincides with the reported intensity peak of the seasonal cycle of the Anticyclone, towards the end of the year (Rahn et al., 2015; Ancapichún and Garcés-Vargas, 2015). Therefore, the mesoscale activity in this region could be directly modulated by the winds. An additional source of intraseasonal (internal) variability in the currents field could be the interaction between the annual extratropical Rossby wave and the mean circulation (Dewitte et al., 2008; Qiu et al., 2013). The actual source of the eddy activity in this region would also deserve further investigation.

Our study also reveals that the most prominent propagating features in DO inside the OMZ at annual frequency is below $\sim 300 \mathrm{~m}$, where the seasonal DO flux follows approximately the theoretical WKB ray paths of the annual ETRW. From that depth, the seasonal variability in physical fluxes becomes 1 order of magnitude larger than that of the biogeochemical fluxes (Fig. 10c). This supports the observation that DO tends to behave as a passive tracer so that vertical displacements of the DO isopleths mimic those of the isotherms, inducing a seasonal DO flux that resembles the energy flux path of the ETRW. This mechanism adds a dimension to the understanding of the OMZ variability, considering that the vertical propagation of ETRW can take place at frequencies ranging from annual (Dewitte et al., 2008) to interannual (Ramos et al., 2008).

We now discuss some implications of our results with regards to current concerns around $\mathrm{OMZ}$ variability at long timescales. A recent study has suggested a trend in the OMZ towards expansion and intensification (Stramma et al., 2008), the forcing mechanism of which remains unclear (Stramma et al., 2010). Observations in the Pacific Ocean also suggest that the OMZ characteristics vary decadally (Stramma et al., $2008,2010)$. Since decadal variability can manifest as a lowfrequency modulation of the seasonal cycle, our study may provide guidance for investigating $\mathrm{OMZ}$ variability at long timescales. In particular, we show that the variability of the $\mathrm{OMZ}$ is not only related to the fluctuations of the equatorial currents system but also impacted by the subtropical variability. This view would link the OMZ low-frequency fluctuations to changes in the midlatitude circulation, in addition to variations in the equatorial Pacific (Stramma et al., 2010). Although we observe a larger amplitude of the seasonal cycle in the subtropics compared to the equatorial region, which could denote a preferential OMZ ventilation through the south, this result should be interpreted in light of a possible overestimation of the ventilation at that boundary in our simulation. We also note that the relative contribution of the mean DO flux and the DO eddy flux exhibit significant interannual fluctuations at the OMZ boundaries (not shown), which suggests that eddy-induced DO flux may not be the only key player for understanding long-term trend in the OMZ. It is interesting to note that, so far, it has been difficult to reconcile the observed trend in the OMZ with the trend simulated by the current generation of coupled models (Stramma et al., 2012), which has been attributed to biases in the mean circulation and inadequate remineralization representation (Cocco et al., 2013; Cabré et al., 2015). Our results 
support the view that such discrepancy may partly originate from the inability of the low-resolution models to account for the DO eddy flux and its modulation. Regional modeling experiments also showed that eddy activity can be modulated at ENSO and decadal timescales (Combes et al., 2015; Dewitte et al., 2012). This issue would certainly require further investigation and could benefit from the experimentation with our coupled model platform. This is planned for future work.

Lastly, the seasonal changes in the OMZ evidenced in this work are associated with a seasonal change of the oxycline depth (and an oxycline intensity change; not shown), which can be considered a proxy for the production of greenhouse gases $\left(\mathrm{CO}_{2}\right.$ and $\left.\mathrm{N}_{2} \mathrm{O}\right)$ inside the OMZ (e.g., Paulmier et al., 2011; Kock et al., 2016). Our results suggest that the impact of the $\mathrm{OMZ}$ on the atmosphere through the production of climatically active gases, such as $\mathrm{CO}_{2}$ and $\mathrm{N}_{2} \mathrm{O}$, would be seasonally damped during austral winter due to a deepening of the oxycline and a weakening of its intensity.

\section{Summary and conclusions}

A high-resolution coupled physical/biogeochemical model experiment is used to document the seasonal variability of the OMZ off Peru. The annual harmonic of DO reveals three main regions with enhanced amplitude or specific propagation characteristics, suggesting distinct dynamical regimes: (1) the coastal domain, (2) the offshore ocean below $400 \mathrm{~m}$ and (3) at the southern and northern boundaries. In the coastal portion of the $\mathrm{OMZ}$, the seasonal variability is related to the local wind forcing and therefore follows to a large extent the paradigm of upwelling triggered productivity, followed by remineralization. It is shown in particular that DO peaks in austral winter, which is associated with horizontal and vertical diffusion induced by both the increase in baroclinic instability and intraseasonal wind activity. This is counterintuitive with regards to the seasonality of the alongshore upwelling favorable winds also peaking in austral winter, which would tend to favor the intrusion of deoxygenated waters from the open-ocean OMZ to the shelf. Instead, the coastal domain can be viewed as a source of DO in austral winter for the OMZ through offshore transport. The latter is induced by eddies that are triggered by the instabilities of the PUC. In the model, the offshore DO eddy flux has a marked seasonal cycle that is in phase with the seasonal cycle of the DO along the coast, implying that the coastal domain, viewed here as the eastern boundary of the OMZ, is a source of seasonal variability for the OMZ. This appears to operate effectively in the upper $300 \mathrm{~m}$. Below that depth, the DO eddy flux is much reduced due to both a much weaker eddy activity and a very low DO concentration. In contrast, a mean seasonal DO flux is observed and exhibits propagating features reminiscent of the vertical propagation of energy associated with the annual ETRW.
In the upper $300 \mathrm{~m}$, the OMZ seasonal variability is also associated with the DO eddy flux at the OMZ meridional boundaries where it is the most intense. We find that the seasonal cycle in DO eddy flux peaks in austral winter at the northern boundary, while it peaks a season later at the southern boundary. Additionally, the amplitude of the seasonal cycle in DO eddy flux is larger at the southern boundary than at the northern boundary. The schematic of Fig. 20 summarizes the main processes documented in this paper to explain the seasonality of the OMZ.

Acknowledgements. Oscar Vergara was supported by a doctoral scholarship from the National Chilean Research and Technology Council (CONICYT) through the program Becas Chile (scholarship 72130138). The authors are thankful for the financial support received from the Centre National d'Etudes Spatiales (CNES). Boris Dewitte acknowledges support from FONDECYT (project 1151185). Marcel Ramos acknowledges support from FONDECYT (project 1140845) and Chilean Millennium Initiative (NC120030). Oscar Pizarro acknowledges support from the FONDECYT 1121041 project and the Chilean Millennium Initiative (IC-120019). The authors thank the two anonymous reviewers for their constructive comments that helped improving the manuscript.

Edited by: K. Fennel

Reviewed by: two anonymous referees

\section{References}

Ancapichún, S. and Garcés-Vargas, J.: Variability of the Southeast Pacific Subtropical Anticyclone and its impact on sea surface temperature off north-central Chile, Cienc. Mar., 41, 1-20, doi:10.7773/cm.v41i1.2338, 2015.

Arévalo-Martínez, D., Kock, L. A., Löscher, C. R., Schmitz, R. A., and Bange, R. A.: Massive nitrous oxide emissions from the tropical South Pacific Ocean, Nat. Geosci., 8, 530-533, doi:10.1038/NGEO2469, 2015.

Bettencourt, J. H., López, C., Hernández-García, E., Montes, I., Sudre, J., Dewitte, B., Paulmier A., and Garçon, V.: Boundaries of the Peruvian Oxygen Minimum Zone shaped by coherent mesoscale dynamics, Nat. Geosci., 8, 937-940,, doi:10.1038/ngeo2570, 2015.

Bianchi, D., Dunne, J. P., Sarmiento, J. L., and Galbraith, E. D.: Data-based estimates of suboxia, denitrification, and $\mathrm{N}_{2} \mathrm{O}$ production in the ocean and their sensitivities to dissolved $\mathrm{O}_{2}$, Global Biogeochem. Cy., 26, GB2009, doi:10.1029/2011GB004209, 2012.

Bianucci, L., Fennel, K., and Denman, K. L.: Role of sediment denitrification in water column oxygen dynamics: comparison of the North American East and West Coasts, Biogeosciences, 9, 26732682, doi:10.5194/bg-9-2673-2012, 2012.

Brandt, P., Bange, H. W., Banyte, D., Dengler, M., Didwischus, S.-H., Fischer, T., Greatbatch, R. J., Hahn, J., Kanzow, T., Karstensen, J., Körtzinger, A., Krahmann, G., Schmidtko, S., Stramma, L., Tanhua, T., and Visbeck, M.: On the role of circulation and mixing in the ventilation of oxygen minimum zones with 
a focus on the eastern tropical North Atlantic, Biogeosciences, 12, 489-512, doi:10.5194/bg-12-489-2015, 2015.

Cabré, A., Marinov, I., Bernardello, R., and Bianchi, D.: Oxygen minimum zones in the tropical Pacific across CMIP5 models: mean state differences and climate change trends, Biogeosciences, 12, 5429-5454, doi:10.5194/bg-12-5429-2015, 2015.

Cambon G., Goubanova, K., Marchesiello, P., Dewitte, B., Illig, S., and Echevin, V.: Assessing the impact of downscaled winds on a regional ocean model simulation of the Humboldt system, Ocean Model., 65, 11-24, 2013.

Chavez, F. P., Bertrand, A., Guevara-Carrasco, R., Soler, P., and Csirke, J.: The northern Humboldt Current System: Brief history, present status and a view towards the future, Prog. Oceanogr., 79, 95-105, 2008.

Chaigneau, A. and Pizarro, O.: Eddy characteristics in the eastern South Pacific, J. Geophys. Res., 110, C06005, doi:10.1029/2004JC002815, 2005.

Chaigneau, A., Eldin G., and Dewitte, B.: Eddy activity in the four major upwelling systems from satellite altimetry (1992-2007), Prog. Oceanogr., 83, 117-123, doi:10.1016/j.pocean.2009.07.012, 2009.

Cocco, V., Joos, F., Steinacher, M., Frölicher, T. L., Bopp, L., Dunne, J., Gehlen, M., Heinze, C., Orr, J., Oschlies, A., Schneider, B., Segschneider, J., and Tjiputra, J.: Oxygen and indicators of stress for marine life in multi-model global warming projections, Biogeosciences, 10, 1849-1868, doi:10.5194/bg-10-18492013, 2013.

Colas, F., McWillimas, J. C., Capet, X., and Kurian, J.: Heat balance and eddies in the Peru-Chile current system, Clim. Dynam., 39, 509-529, doi:10.1007/s00382-011-1170-6, 2012.

Combes, V., Hormazabal, S., and Di Lorenzo, E.: Interannual variability of the subsurface eddy field in the Southeast Pacific, J. Gephys. Res., 120, 4907-4924, doi:10.1002/2014JC010265, 2015.

Cornejo, M. and Farías, L.: Following the $\mathrm{N}_{2} \mathrm{O}$ consumption in the oxygen minimum zone of the eastern South Pacific, Biogeosciences, 9, 3205-3212, doi:10.5194/bg-9-3205-2012, 2012.

Cornejo, M., Farías, L., and Paulmier, A.: Temporal variability in $\mathrm{N}_{2} \mathrm{O}$ water content and its air-sea exchange in an upwelling area off central Chile $\left(36^{\circ} \mathrm{S}\right)$, Mar. Chem., 101, 85-94, doi:10.1016/j.marchem.2006.01.004, 2006.

Czeschel, R., Stramma, L., Schwarzkopf, F. U., Giese, B. S., Funk, A., and Karstensen, J.: Middepth circulation of the eastern tropical South Pacific and its link to the oxygen minimum zone, J. Geophys. Res., 116, C01015, doi:10.1029/2010JC006565, 2011.

Czeschel, R., Stramma, L., Weller, R. A., and Fischer, T.: Circulation, eddies, oxygen, and nutrient changes in the eastern tropical South Pacific Ocean, Ocean Sci., 11, 455-470, doi:10.5194/os11-455-2015, 2015.

daSilva A., Young, A. C., and Levitus, S.: Atlas of surface marine data 1994. Algorithms and procedures. vol. 1 Technical Report 6, US Department of Commerce, NOAA, NESDIS, 1994.

Dewitte B., Ramos, M., Echevin, V., Pizarro, O., and duPenhoat, Y.: Vertical structure variability in a seasonal simulation of a medium-resolution regional model simulation of the South Eastern Pacific, Prog. Oceanogr., 79, 120-137, 2008.

Dewitte, B., Illig, S.,Renault, L., Goubanova, K., Takahashi, K., Gushchina, D., Mosquera, K., and Purca, S.: Modes of covariability between sea surface temperature and wind stress intraseasonal anomalies along the coast of Peru from satellite observations (2000-2008), J. Geophys. Res., 116, C04028, doi:10.1029/2010JC006495, 2011.

Dewitte, B., Vazquez-Cuervo, J., Goubanova, K., Illig, S., Takahashi, K., Cambon, G., Purca, S., Correa, D., Gutiérrez, D., Sifeddine, A., and Ortlieb, L.: Change in El Nino flavours over 1958-2008: Implications for the long-term trend of the upwelling off Peru, Deep-Sea Res. Pt. II, 77-80, 143-156, doi:10.1016/j.dsr2.2012.04.011, 2012.

Dunn J. R. and Ridgway, K. R.: Mapping ocean properties in regions of complex topography, Deep-Sea Res. Pt. I, 49, 591-604, 2002.

Dunne, J. P., Armstrong, R. A., Gnanadesikan, A., and Sarmiento, J. L.: Empirical and mechanistic models for the particle export ratio, Global Biogeochem. Cy., 19, GB4026, doi:10.1029/2004gb002390, 2005.

Duteil, O. and Oschlies, A.: Sensitivity of simulated extent and future evolution of marine suboxia to mixing intensity, Geophys. Res. Lett., 38, L06607, doi:10.1029/2011GL046877, 2011.

Duteil, O., Schwarzkopf, F. U., Böning, C. W., and Oschlies, A.: Major role of the equatorial current system in setting oxygen levels in the eastern tropical Atlantic Ocean: A highresolution model study, Geophys. Res. Lett., 41, 2033-2040, doi:10.1002/2013GL058888, 2014.

Echevin, V., Aumont, O., Ledesma, J., and Flores, G.: The seasonal cycle of surface chlorophyll in the Peruvian upwelling system: A modelling study, Progr. Oceanogr., 79, 2-4, 167-176, 2008.

Echevin, V., Colas, F., Chaigneau, A., and Penven, P.: Sensitivity of the Northern Humboldt Current System nearshore modeled circulation to initial and boundary conditions, J. Geophys. Res., 116, C07002, doi:10.1029/2010JC006684, 2011.

Eliassen, A. and Palm, E.: On the transfer of energy in stationary mountain waves, Geofys. Publ., 22, 1-23, 1960.

Farías, L., Paulmier, A., and Gallegos, M.: Nitrous oxide and Nnutrient cycling in the oxygen minimum zone off northern Chile, Deep-Sea Res. Pt. I, 54, 164-180, doi:10.1016/j.dsr.2006.11.003, 2007.

Fuenzalida, R., Schneider, W., Garces-Vargas, J., Bravo, L., and Lange, C.: Vertical and horizontal extension of the oxygen minimum zone in the eastern South Pacific Ocean, Deep-Sea Res. Pt. II, 56, 992-1003, doi:10.1016/j.dsr2.2008.11.001, 2009.

García, H. E. and Gordon, L. I.: Oxygen solubility in seawater - better fitting equations, Limnol. Oceanogr., 37, 1307-1312, 1992.

Goubanova, K., Echevin, V., Dewitte, B., Codron, F., Takahashi, K., Terray, P., and Vrac, M.: Statistical downscaling of sea-surface wind over the Peru-Chile upwelling region: diagnosing the impact of climate change from the IPSL-CM4 model, Clim. Dynam., 36, 1365, doi:10.1007/s00382-010-0824-0, 2011.

Gruber, N.: The marine nitrogen cycle: Overview of distributions and processes, in: Nitrogen in the marine environment, second Edn., edited by: Capone, D. G., Bronk, D. A., Mulholland, M. R., and Carpenter, E. J., Elsevier, Amsterdam, 1-50, 2008.

Gruber, N., Lachkar, Z., Frenzel, H., Marchesiello, P., Münnich, M., McWilliams, J. C., Nagai, T., and Plattner, G. K.: Eddy-induced reduction of biological production in eastern boundary upwelling systems, Nat. Geosci., 4, 787-792, doi:10.1038/ngeo1273, 2011.

Gutiérrez, D., Enriquez, E., Purca, S., Quipuzcoa, L., Marquina, R., Flores, G., and Graco, M.: Oxygenation episodes on the conti- 
nental shelf of central Peru: remote forcing and benthic ecosystem response, Prog. Oceanogr., 79, 177-189, 2008.

Gutiérrez, D., Bouloubassi, I., Sifeddine, A., Purca, S., Goubanova, K., Graco, M., Field, D., Mejanelle, L., Velazco, F., Lorre, A., Salvatteci, R., Quispe, D., Vargas, G., Dewitte, B., and Ortlieb, L.: Coastal cooling and increased productivity in the main upwelling zone off Peru since the mid-twentieth century, Geophys. Res. Lett., 38, L07603, doi:10.1029/2010GL046324, 2011.

Gutknecht, E., Dadou, I., Le Vu, B., Cambon, G., Sudre, J., Garçon, V., Machu, E., Rixen, T., Kock, A., Flohr, A., Paulmier, A., and Lavik, G.: Coupled physical/biogeochemical modeling including $\mathrm{O}_{2}$-dependent processes in the Eastern Boundary Upwelling Systems: application in the Benguela, Biogeosciences, 10, 35593591, doi:10.5194/bg-10-3559-2013, 2013a.

Gutknecht, E., Dadou, I., Marchesiello, P., Cambon, G., Le Vu, B., Sudre, J., Garçon, V., Machu, E., Rixen, T., Kock, A., Flohr, A., Paulmier, A., and Lavik, G.: Nitrogen transfers off Walvis Bay: a 3-D coupled physical/biogeochemical modeling approach in the Namibian upwelling system, Biogeosciences, 10, 41174135, doi:10.5194/bg-10-4117-2013, 2013 b.

Henley, B. J., Gergis, J., Karoly, D. J., Power, S. B., Kennedy, J., and Folland, C. K.: A Tripole Index for the Interdecadal Pacific Oscillation, Clim. Dynam., 45, 3077-3090, doi:10.1007/s00382015-2525-1, 2015.

Henson, S. A., Sanders, R., and Madsen, E.: Global patterns in efficiency of particulate organic carbon export and transfer to the deep ocean, Global Biogeochem. Cy., 26, GB1028, doi:10.1029/2011gb004099, 2012.

Illig, S., Dewitte, B., Goubanova, K., Cambon, G., Boucharel, J., Monetti, F., Romero, C., Purca, S., and Flores, R.: Forcing mechanisms of intraseasonal SST variability off central Peru in 2000-2008, J. Geophys. Res., 119, 3548-3573, doi:10.1002/2013JC009779, 2014.

Karstensen, J., Stramma, L., and Visbeck, M.: Oxygen minimum zones in the eastern tropical Atlantic and Pacific oceans, Progr. Oceanogr., 77, 331-350, 2008.

Karstensen, J., Fiedler, B., Schütte, F., Brandt, P., Körtzinger, A., Fischer, G., Zantopp, R., Hahn, J., Visbeck, M., and Wallace, D.: Open ocean dead zones in the tropical North Atlantic Ocean, Biogeosciences, 12, 2597-2605, doi:10.5194/bg-12-2597-2015, 2015.

Kelly, K., Beardsley, R., Limeburner, R., and Brink, K.: Variability of the near-surface eddy kinetic energy in the California Current based on altimetric, drifter and moored data, J. Geophys. Res., 103, 13067-13083, 1998.

Kock, A., Arévalo-Martínez, D. L., Löscher, C. R., and Bange, H. W.: Extreme $\mathrm{N}_{2} \mathrm{O}$ accumulation in the coastal oxygen minimum zone off Peru, Biogeosciences, 13, 827-840, doi:10.5194/bg-13827-2016, 2016.

Large, W. G., McWilliams, J. C., and Doney, S. C.: Oceanic vertical mixing: A review and a model with a nonlocal boundary layer parameterization, Rev. Geophys., 32, 363-403, doi:10.1029/94RG01872, 1994.

Law, C. S., Brévière, E., de Leeuw, G., Garçon, V., Guieu, C., Kieber, D. J., Kontradowitz, S., Paulmier, A., Quinn, P. K., Saltzman, E. S., Stefels, J., and von Glasow, R.: Evolving research directions in Surface Ocean - Lower Atmosphere (SOLAS) science, Environ. Chem., 10, 1-16, doi:10.1071/EN12159, 2013.
Libes, S. M.: An Introduction to Marine Biogeochemistry, John Wiley and Sons, New York, 734 pp., 1992.

Llanillo, P. J., Karstensen, J., Pelegrí, J. L., and Stramma, L.: Physical and biogeochemical forcing of oxygen and nitrate changes during El Niño/El Viejo and La Niña/La Vieja upper-ocean phases in the tropical eastern South Pacific along $86^{\circ} \mathrm{W}$, Biogeosciences, 10, 6339-6355, doi:10.5194/bg-10-6339-2013, 2013.

Luyten, J. R., Pedlosky, J., and Stommel, H.: The ventilated thermocline, J. Phys. Oceanogr., 13, 292-309, 1983.

McClain, C. R., Cleave, M. L., Feldman, G. C., Gregg, W. W., Hooker, S. B., and Kuring, N.: Science quality SeaWiFS data for global biosphere research, Sea Technol., 39, 10-16, 1998.

Montes, I., Colas, F., Capet, X., and Schneider, W.: On the pathways of the equatorial subsurface currents in the Eastern Equatorial Pacific and their contributions to the Peru-Chile Undercurrent, J. Geophys. Res., 115, C09003, doi:10.1029/2009JC005710, 2010.

Montes, I., Dewitte, B., Gutknecht, E., Paulmier, A., Dadou, I., Oschlies, A., and Garçon, V.: High-resolution modeling of the Eastern Tropical Pacific oxygen minimum zone: Sensitivity to the tropical oceanic circulation, J. Geophys. Res.-Oceans, 119, 5515-5532, doi:10.1002/2014JC009858, 2014.

Morales, C. E., Hormazabal, S. E., and Blanco, J.: Interannual variability in the mesoscale distribution of the depth of the upper boundary of the oxygen minimum layer off northern Chile (18-24S): Implications for the pelagic system and biogeochemical cycling, J. Mar. Res., 57, 909-932, doi:10.1357/002224099321514097, 1999.

Morel, A. and Berthon, J. F.: Surface pigments, algal biomass profiles, and potential production of euphotic layer: Relationship reinvestigated in view of remote-sensing applications, Limnol. Oceanogr., 34, 1545-1562, 1989.

Nagai, T., Gruber, N., Frenzel, H., Lachkar, Z., McWilliams, J. C., and Plattner, G.-K.: Dominant role of eddies and filaments in the offshore transport of carbon and nutrients in the California Current System, J. Geophys. Res.-Oceans, 120, 5318-5341, doi:10.1002/2015JC010889, 2015.

Nerem, R. S., Chambers, D. P., Choe, C., and Mitchum, G. T.: Estimating mean sea level change from the TOPEX and Jason altimeter missions, Mar. Geod., 33, Supplement 1, 435-446, 2010

O’Reilly, J. E., Maritorena, S., Siegel, D., O’Brien, M. O., Toole, D., Mitchell, B. G., Kahru, M., Chavez, F., Strutton, P. G., Cota, G. F., Hooker, S. B., McClain, C., Carder, K., Muller-Karger, F., Harding, L., Magnuson, A., Phinney, D., Moore, G., Aiken, J., Arrigo, K. R., Letelier, R. M., and Culver, M.: Ocean chlorophyll a algorithms for SeaWiFS, OC2, and OC4: Version 4, in: SeaWiFS Postlaunch Calibration and Validation Analyses, Part 3, NASA Tech. Memo 2000-206892, vol. 11, edited by: Hooker, B., and Firestone, E. R., NASA, Goddard Space Flight Center, Greenbelt, Maryland, 9-19, 2000.

Paulmier, A. and Ruiz-Pino, D.: Oxygen minimum zones (OMZs) in the modern ocean, Prog. Oceanogr., 80, 3-4, 113-128, doi:10.1016/j.pocean.2008.08.001, 2009.

Paulmier, A., Ruiz-Pino, D., Garçon, V., and Farías, L.: Maintaining of the East South Pacific Oxygen Minimum Zone (OMZ) off Chile, Geophys. Res. Lett., 33, L20601, doi:10.1029/2006GL026801, 2006.

Paulmier, A., Ruiz-Pino, D., and Garçon, V.: The Oxygen Minimum Zone (OMZ) off Chile as intense source of $\mathrm{CO}_{2}$ and $\mathrm{N}_{2} \mathrm{O}$, Cont. Shelf Res., 28, 2746-2756, 2008. 
Paulmier, A., Ruiz-Pino, D., and Garçon, V.: $\mathrm{CO}_{2}$ maximum in the oxygen minimum zone (OMZ), Biogeosciences, 8, 239-252, doi:10.5194/bg-8-239-2011, 2011.

Penven, P., Echevin, V., Pasapera, J., Colas, F., and Tam, J.: Average circulation, seasonal cycle, and mesoscale dynamics of the Peru Current System: a modeling approach, J. Geophys. Res., 110, C10021, doi:10.1029/2005JC002945, 2005.

Pizarro, O., Shaffer, G., Dewitte, B., and Ramos, M.: Dynamics of seasonal and interannual variability of the Peru-Chile Undercurrent, Geophys. Res. Lett., 29, 1581, doi:10.1029/2002GL014790, 2002.

Prince, E. D. and Goodyear, C. P.: Hypoxia-based habitat compression of tropical pelagic fishes, Fish. Oceanogr., 15, 451-464, doi:10.1111/j.1365-2419.2005.00393.x, 2006.

Qiu, B., Chen, S., and Sasaki, H.: Generation of the North Equatorial Undercurrent jets by triad baroclinic Rossby wave interactions, J. Phys. Oceanogr., 43, 2682-2698, doi:10.1175/JPO-D13-099.1, 2013.

Rahn, D., Rosenblüth, B., and Rutllant, J.: Detecting Subtle Seasonal Transitions of Upwelling in North-Central Chile, J. Phys. Oceanogr., 45, 854-867, 2015.

Ramos, M., Dewitte, B., Pizarro, O., and Garric, G.: Vertical propagation of extratropical Rossby waves during the 1997-1998 El Niño off the west coast of South America in a mediumresolution OGCM simulation, J. Geophys. Res., 113, C08041, doi:10.1029/2007JC004681, 2008.

Resplandy, L., Lévy, M., Bopp, L., Echevin, V., Pous, S., Sarma, V. V. S. S., and Kumar, D.: Controlling factors of the oxygen balance in the Arabian Sea's OMZ, Biogeosciences, 9, 50955109, doi:10.5194/bg-9-5095-2012, 2012.

Reynolds, R. W., Smith, T. M., Liu, C., Chelton, D. B., Casey, K. S., and Schlax, M. G.: Daily high-resolution blended analyses for sea surface temperature, J. Climate, 20, 5473-5496, 2007.

Richter, I.: Climate model biases in the eastern tropical oceans: causes, impacts and ways forward, WIREs Clim. Change, 6, 345-358, doi:10.1002/wcc.338, 2015.

Ridgway K. R., Dunn, J. R., and Wilkin, J. L.: Ocean interpolation by four-dimensional least squares - Application to the waters around Australia, J. Atmos. Ocean. Tech., 19, 1357-1375, 2002.

Shchepetkin, A. F. and McWilliams, J. C.: The regional oceanic modeling system: a split-explicit, free-surface, topographyfollowing-coordinate ocean model, Ocean Model., 9, 347-404, 2005.
Shchepetkin, A. F. and McWilliams, J. C.: Correction and commentary for "Ocean forecasting in terrain-following coordinates: Formulation and skill assessment of the regional ocean modeling system" by Haidvogel et al., J. Comp. Phys., 227, 3595-3624, 2009.

Siedlecki, S. A., Banas, N. S., Davis, K. A., Giddings, S., Hickey, B. M., MacCready, P., Connolly, T., and Geier, S.: Seasonal and interannual oxygen variability on the Washington and Oregon continental shelves, J. Geophys. Res.-Oceans, 120, 608-633, doi:10.1002/2014JC010254, 2015.

Stramma, L., Johnson, G. C., Sprintall, J., and Mohrholz, V.: Expanding oxygen-minimum zones in the tropical oceans, Science, 320, 655-658, 2008.

Stramma, L., Johnson, G. C., Firing, E., and Schmidtko, S.: Eastern Pacific oxygen minimum zones: Supply paths and multidecadal changes, J. Geophys. Res., 115, C09011, doi:10.1029/2009JC005976, 2010.

Stramma, L., Oschlies, A., and Schmidtko, S.: Mismatch between observed and modeled trends in dissolved upper-ocean oxygen over the last $50 \mathrm{yr}$, Biogeosciences, 9, 4045-4057, doi:10.5194/bg-9-4045-2012, 2012.

Stramma, L., Bange, H. W., Czeschel, R., Lorenzo, A., and Frank, M.: On the role of mesoscale eddies for the biological productivity and biogeochemistry in the eastern tropical Pacific Ocean off Peru, Biogeosciences, 10, 7293-7306, doi:10.5194/bg-10-72932013, 2013.

Stramma, L., Weller, R. A., Czeschel, R., and Bigorre, S.: Eddies and an extreme water mass anomaly observed in the eastern south Pacific at the Stratus mooring, J. Geophys. Res.-Oceans, 119, 1068-1083, 2014.

Thomsen, S., Kanzow, T., Krahmann, G., Greatbatch, R. J., Dengler, M., and Lavik, G.: The formation of a subsurface anticyclonic eddy in the Peru-Chile Undercurrent and its impact on the near-coastal salinity, oxygen, and nutrients distributions, J. Geophys. Res.-Oceans, 121, 476-501, doi:10.1002/2015JC010878, 2016. Thomsen, S., Kanzow, T., Krahmann, G., Greatbatch, R. J., Dengler, M., and Lavik, G.: The formation of a subsurface anticyclonic eddy in the Peru-Chile Undercurrent and its impact on the near-coastal salinity, oxygen, and nutrients distributions, J. Geophys. Res.-Oceans, 121, 1, 476-501, doi:10.1002/2015JC010878, 2016. 